\title{
Communication Strategies and Proficiency Levels in L2 Speech Production: a systematic relationship
}

\author{
Estratégias de Comunicação e Níveis de Proficiência na \\ produção oral em língua estrangeira: uma relação \\ sistemática
}

Gicele Vergine Vieira Prebianca Universidade Federal de Santa Catarina

\begin{abstract}
This study investigates the relationship between the use of Communication Strategies (CSs) and the proficiency level of L2 ${ }^{1}$ learners. In order to pursue this objective, three speech samples of 30 English L2 learners were collected over a period corresponding to an academic semester. Participants consisted of three groups of 10 learners each and were selected from three different proficiency levels: pre-intermediate, intermediate, and advanced. Three oral narratives were used to elicit learners' L2 oral production, in three different sessions conducted with a one-month interval between each other. Data were analysed qualitatively and quantitatively according to Dörnyei and Kormos's (1998) taxonomy for CSs classification. Analysis revealed a common set of CSs systematically used across sessions and proficiency levels with a high frequency of occurrence.
\end{abstract}

Keywords

Communication strategies; Speech production; Proficiency, L2. 


\section{Resumo}

Este estudo investiga a relação entre o uso de Estratégias de Comunicação (EC) e o nível de proficiência dos aprendizes de língua estrangeira. Para isso, três amostras de fala de 30 aprendizes de inglês como língua estrangeira foram coletadas em um período correspondente a um semestre letivo. Os participantes foram divididos em três grupos de 10 aprendizes cada, de acordo com três diferentes níveis de proficiência: pré-intermediário, intermediário e avançado. Três narrativas orais foram utilizadas para elicitar a produção oral dos aprendizes, em três sessões de coleta de dados conduzidas com um mês de intervalo entre uma e outra.Os dados foram analisados qualitativa e quantitativamente, seguindo a classificação de EC proposta por Dörnyei e Kormos (1998). Os resultados revelaram que um grupo comum de EC foi sistematicamente utilizado com uma alta frequência de ocorrência, em todas as sessões de coleta de dados e em todos os três níveis de proficiência analisados.

\section{Palavras-chave}

Estratégias de comunicação; Produção oral; Proficiência, L2. 


\section{Introduction}

$\mathrm{T}$ he issue of strategic behavior has been a major concern in the field of speech production. One way of looking at strategic competence has been through the study of communication strategies. Research on this topic has contributed to shedding light on a whole range of issues, such as the scope of the construct, the defining criteria to identify the different types of CS and the frameworks and taxonomies to classify them.

Over the last four decades, communication strategies have been conceptualized in many different ways a communicative-approach product (SELINKER, 1972); message-adjustment mechanisms (VARADI, 1983); interactional strategies (TARONE, 1980); cognitive conscious plans (FAERCH and KASPER, 1983); problem-solving devices (DÖRNYEI and KORMOS, 1998), being a case in point. In the present study, CS are defined as tools to help L2 users to overcome possible problems in communication as well as to optimize the use of language in their communicative enterprises (DÖRNYEI and KORMOS, 1998; KASPER and KELLERMAN, 1997).

The significance of the present study lies in the importance of investigating whether L2 learners at distinct stages of L2 development deal with their communicative problems in a similar fashion. Therefore, the main objective of the present study is to analyze which types of communication strategies are applied by pre-intermediate, intermediate, and advanced learners when communicating in an L2 and their respective frequency of occurrence. Results of the present study may shed light on how to maximize the use of oral tasks in the classroom. Knowing why and how learners make use of certain strategies may be useful in helping teachers to choose appropriate tasks that would allow learners to cope with their difficulties in communication. In addition, the present study may reveal a set of CSs which might be profitably used by L 2 learners in the improvement of their speech performance in the second language. 
This paper is organized into five main sections. Following this introductory section, theoretical and empirical issues on Communication Strategies are reviewed in section 2 . Section 3 describes the research questions, participants, and the method for data collection and analysis. Section 4 reports the results and discusses the findings. Finally, in section 5, some general considerations addressing the main conclusions, limitations of the study and suggestions for further research are proposed.

\section{Review of the Literature}

Attempting to examine second-language learners' systematic use of strategies while solving communicative problems, Bialystok (1983) posited a very relevant question: Who uses which strategies, when and with what effect? (p. 103). One of her major concerns was to establish the conditions which might lead learners to select a particular strategy at the expense of another. Bialystok argued that CSs included "all attempts to manipulate a limited linguistic system in order to promote communication" (p. 102). In order to elicit the CSs used to supply the lack of appropriate L2 vocabulary items, Bialystok carried out a picture reconstruction task, in which participants were asked to describe a picture so that a French native-speaker could reconstruct it. Results yielded a typology for CSs governed by the source of information underlying learners' CS use. Therefore, strategies such as language switch, foreignizing and transliteration were considered to be grounded on learners' knowledge of their native language (L1-based strategies). Semantic contiguity, description and word coinage were based on learners' knowledge of the target language (L2-based strategies), and paralinguistic strategies based on non-linguistic or contextual information. Concerning the issue of who uses which strategy, when and with what effect, Bialystok showed that differences in the mean number of strategies were not statistically significant in terms of language proficiency; however, more advanced learners tended to employ consistently more L2-based strategies than the less proficient ones. Despite the fact that the level of proficiency was considered to bias learners' selection of CSs, it did not predict this choice. Hence, it seemed that, in Bialystok's study, strategy use was determined, in part, by specifications of the target concepts being communicated. In addition, CSs seemed to be more effective for learners with greater control over the L2. 
Paribakht (1985) also analyzed the relationship between L2 learners' proficiency level and their use of CSs. The study consisted of a concept-description task, in which L2 English learners were expected to convey the meaning of twenty lexical items - ten abstract and ten concrete items, to a native interlocutor. As evidenced by the author, L2 learners' use of CSs drew upon four distinct sources of knowledge: (1) knowledge of semantic features - which was defined as the linguistic approach; (2) knowledge of context - which referred to the contextual approach; (3) knowledge of the world-labeled as the conceptual approach; and (4) knowledge of meaningful gestures - the so-called mime approach (p. 135). Results further indicated that more proficient learners applied a greater amount of CSs from the linguistic approach due to their deeper knowledge of the L2 being studied. According to Paribakht therefore, learners' communicative competence is a function of their linguistic knowledge. That is, their use of CSs seems to vary according to learner's proficiency level as the amount and quality of linguistic knowledge increase during the learning process.

Following trends in cognitive psychology, Palmberg (1984) designed a study aiming at analyzing the use of CSs as problem-solving mechanisms applied by L 2 learners. He investigated two intermediate learners of English - a girl and a boy, attending a language course in England. In the first phase of the communicative task, the girl was required to instruct the boy in the drawing of three different geometrical shapes. Participants could communicate freely, but were instructed to avoid non-verbal talk. The second phase comprised a retrospection session, in which participants had to discuss the problems they faced during the first phase and plan how the shapes could be communicated in a more efficient way to a third participant. In the third and last phase, the girl and the boy were supposed to instruct another intermediate learner in drawing the same shapes, trying to pursue their plan as much as possible. Data analysis revealed a series of lexical problems during interaction, especially in phases one and three. In the retrospection session, data analysis indicated learners' awareness of the fact that successful communication does not depend only on their ability to use language, but also on speakers' capacity to convey ideas in general (p. 43), suggesting that "learners clearly treated potential language problems and cognitive problems separately when making plans for the use of strategies"(p. 44).

As an attempt to explain L2 learners' resources to cope with lexical problems, Kumaravadivelu (1988) investigated which psychological processes might underlie lexical simplification through learners' use of CSs. Participants 
were undergraduate students in their first year of college. Learners were given fifty minutes to write the story of a movie they had watched and to tell if they had liked it or not. The first drafts of the compositions of ten learners were selected for analysis. These drafts were then reformulated to conform to the L2 linguistic norms and compared to the original texts. Data analysis revealed eight categories of CSs: (1) extended use of lexical items, (2) lexical paraphrase, (3) word coinage, (4) L1 equivalence and (5) Literal translation of L1 idioms. Considering that CSs elicitation was done via written performance, the author proposed three categories that seem to be in accordance with the characteristics of written language; they are: (6) Cl mode of emphasis - "learners' use of two semantically redundant words in the same sentence" (p. 314); (7) Cl mode of linking constructions - "all the ideas (...) are coordinately linked and there is very little subordination" (p. 314), and (8) Cl cohesive devices - "use of cohesive markers peculiar to native cultural thought pattern"(p. 314-315).

According to Kumaravadivelu, the psychological processes underlying CSs 1, 2 and 3 are called Overgeneralization since learners violate the L2 linguistic code and make generalizations in order to communicate the problematic lexical item. Communication strategies 4,5 and 6 are suggested to be governed by the process of Creative transfer, in which learners apply morphological and syntactic features of L1 lexical items in the construction of their L2 counterparts. The psychological process named Cultural Relativity underlies CSs 6,7 and 8 . In this process, learners operate according to the cultural patterns of their native language, thus producing language derived from L1 rhetorical modes (p. 316-317).

Given that Kumaravadivelu's (1988) taxonomy seemed to be too restricted to his specific pool of data, the Nijmegen group (BONGAERTS \& POULISSE, 1989; BONGAERTS, KELLERMAN \& BENTAGLE, 1987; KELLERMAN, 1991; KELLERMAN, BONGAERTS \& POULISSE, 1987; POULISSE, 1987; POULISSE \& SCHILS, 1989; POULISSE, BONGAERTS and KELLERMAN, 1987) proposed another taxonomy based on a large-scale study, including L2 learners' performance in four different tasks, native-language control data, and several methods of data collection (BIALYSTOK, 1990). Their taxonomy was an attempt to meet three specific requirements: (i) parsimony - "the smallest number of strategies that account for the data provides the best description"; (ii) psychological plausibility - "some description of language processing should be directly linked to divisions among strategies", and (iii) generalizability - "the same taxonomy should equally fit data generated through different tasks and using different items and 
be equally appropriate to different sets of learners irrespective of their first or second languages" (BIALYSTOK, 1990, p. 112). The Nijmegen's taxonomy consisted of two strategies: conceptual and linguistic. The conceptual strategies included holistic and analytic strategies. Whereas the former refer to "the use of a single word to substitute for the target" (BIALYSTOK, 1990, p. 111), for instance, rose for flower; the latter occur when "the speaker manipulates the concept and refers to it either by listing (some of) its defining and/or characteristic features (POULISSE and SCHILS, 1989, p.21). As pointed out by Bialystok (1990), the fact that native speakers also showed a tendency to use linguistic strategies and that non-verbal devices were also used to describe the constituents of particular target items led to the reformulation of this category into code strategy.

Similarly, Bialystok (1990) aimed at placing L2 learners' strategic behavior within a framework of language processing. According to her, differences in CSs use reflect differences in language processing and might be explained from two different perspectives. The first one is to consider language use as interactional in nature and, thus, analyzing CSs within discoursal, pragmatic and sociolinguistic patterns. The second perspective is to understand the cognitive mechanisms involved in language processing and acquisition, and therefore consider the psycholinguistic processes underlying strategic language use. In order to explain CSs use taking into account the second perspective, Bialystok (1990) proposed a model of language processing in which language proficiency is achieved by means of two specialized processing components: analysis of linguistic knowledge and control of linguistic processing. Analysis of linguistic knowledge comprises cognitive processes involved in turning implicit mental representations of language into explicit knowledge or symbolic structures independent of meaning. Yet control of linguistic processing refers to language users' ability to direct their attentional resources to specific information, by discarding what is not relevant and selecting what needs to be processed. Developing the capacity to communicate in L2 requires from learners high levels of control, so that they can select appropriate language structures to achieve the specifications of the particular communicative event (p. 125)

Moreover, Bialystok explains that specific language uses present specific cognitive demands. L2 learners may master the processing components of analysis of linguistic knowledge and control of linguistic processing in different degrees, and are therefore more or less likely to complete the task. As suggested by Bialystok (1990), considering that communicating in L2 requires great 
cognitive effort and that $\mathrm{L} 2$ learners differ in their capacity to process language, they are likely to experience several breakdowns in communication, and so apply CSs in order to expand their resources and be able to get their messages across. As pointed out by Bialystok (1990),

Communication strategies are part of the process of ordinary language use. They reflect the ways in which the processing system extends and adapts itself to the demands of communication. Sometimes traces are left as the system strains to achieve the balance between intention and expression. These are the cases in which noticeable gaps are evident between what one is expected to say, or what would normally say under the circumstances, and what one is able to say. This imbalance is a constant feature of the speech of young children and second-language learners (p. 131).

Considering that $\mathrm{L} 2$ learners' limited processing capacity yields CSs use, Bialystok (1990) suggests a taxonomy in which strategies are linked to the processes of analyses and control of language, thus classifying them as analysisbased strategies and control-based strategies. Whereas the former include L2 learners' attempt to convey the intended concept by exploiting its relational defining features, the latter comprise strategies that reallocate learners' attention to other linguistic systems that will serve the same communicative intention. Strategies within the analysis-based strategy category concern circumlocution, paraphrase, transliteration and word coinage, and the ones within the controlbased strategy category are code switching, appealing for assistance, ostensive definition and mime (p. 132-133). Such CSs, defined by Bialystok as analysis-based and control-based, appear to correspond to the conceptual and linguistic strategies suggested by the Nijmegen group, since in order for L2 speakers to transform mental representations of language into explicit knowledge and resort to different linguistic systems when necessary, they need to use their knowledge of the world and to allocate their attention to specific language particularities, and therefore use conceptual and linguistic information.

Poulisse (1993) challenges Nijmegen's and Bialystok's taxonomies, by claiming that they are not clear in terms of the psychological processes underlying CSs use. According to the researcher, such proposals fail to distinguish between strategic and nonstrategic language use. Hence, assuming that CSs are "strategies 
used to overcome problems resulting from an inadequate knowledge of the second language (L2)" (p. 157), Poulisse argues that a model of oral communication is essential to explain L2 learner's strategic behavior. Consequently, she proposes a taxonomy based on an adaptation of Levelt's (1989) theory of speech production for L1 (see LEVELT, 1989, chapter 1 for an overview of speech processing in first language) and suggests that CSs are applied when speakers experience problems in accessing the appropriate lexical item necessary to encode the intended message, either because this item does not exist in their mental lexicon or because it cannot be temporarily retrieved. At this time, therefore, speakers become aware of the gap in their interlanguage system.

As explained by Poulisse, it is not totally understood at which phase of the speech production process speakers are signaled that they are running into problems. One way of explaining this would assume that there is a connection between the conceptualizer and the mental lexicon, which would enable speakers to avoid problems in advance by conceptualizing messages that do not require the problematic lexical item. However, as Levelt's model is considered strictly modular, that is, it does not allow feedback among processing components, this solution has to be left aside. Another alternative is to consider that the conceptualizer is warned of problems regarding lexical access via the SpeechComprehension System. This may be possible due to the time lexical information is kept in a buffer zone before being encoded, thus providing enough time for the monitor to work. When this occurs, L2 speakers have three options. First, they may apply the CS of message abandonment - speakers stop the process and give up the message as a whole. Second, L2 speakers may appeal for assistance, that is, they ask their interlocutor for help in order to continue encoding the message. And, third, they may use compensatory strategies - alternative means of conveying their original communicative goals.

Compensatory Strategies are classified by Poulisse as substitution strategies - when the speaker changes or omits one or more features of a particular cluster of words; substitution plus strategies - when the speaker applies L1 or L2 morphological and/or phonological features to the selected lexical item; and Reconceptualization - when the speaker replaces, adds or deletes more than one cluster of the preverbal message (p. 181).

Following Poulisse (1993), Dörnyei and Kormos (1998), discuss CSs as problem-management mechanisms applied by second-language speakers in L2 communication. The authors propose a framework that aims at providing a 
process-oriented set of CSs, based on Levelt's (1989) model of speech production and its L2 adaptations. Four sources of problems in L2 communication which were identified by the authors - (1) L2 resource deficits, (2) processing time pressure, (3) perceived deficiencies in the speaker's own performance and (4) perceived deficiencies in the interlocutor's performance, are connected to the pre and post articulatory phases of Levelt's speech processing model. An advantage of this approach is that these four sources of problems are not restricted to the use of strategies that cope only with referential communication, more specifically, those concerning lexical difficulties, as in the taxonomies offered by Bialystok (1990), the Nijmegen group and Poulisse's (1993). This taxonomy seems to be broader in scope, since it gathers the most relevant categories of CSs presented in the literature. For these reasons, Dörnyei and Kormos' taxonomy was chosen to identify and classify the data of the present study.

Inserting the four sources of problems into Levelt's proposal, we have:

\begin{tabular}{lll}
\hline Problem type & $\begin{array}{l}\text { Phases of speech } \\
\text { production according } \\
\text { to Levelt (1989) }\end{array}$ & $\begin{array}{l}\text { Problem-solving mechanisms } \\
\text { (PSM) or CSs according to } \\
\text { Dörnyei and Kormos (1998) }\end{array}$ \\
\hline Resource deficit & $\begin{array}{l}\text { Planning and encoding } \\
\text { the preverbal message }\end{array}$ & $\begin{array}{l}\text { - Lexical PSM } \\
\text { - Grammatical PSM } \\
\text { - Phonological and } \\
\text { Articulatory PSM }\end{array}$ \\
\hline Processing time pressure & Planning and encoding & - Stalling Mechanisms \\
\hline $\begin{array}{l}\text { Deficiency in one's own } \\
\text { language }\end{array}$ & $\begin{array}{l}\text { Monitoring the phonetic } \\
\text { plan and articulated speech }\end{array}$ & $\begin{array}{l}\text { - Self-corrections } \\
\text { - Check Questions }\end{array}$ \\
\hline $\begin{array}{l}\text { Deficiency in the } \\
\text { interlocutor's performance }\end{array}$ & Post-articulatory monitoring & $\begin{array}{l}\text { - Meaning-negotiation } \\
\text { Mechanisms }\end{array}$ \\
\hline
\end{tabular}

\section{The study}

The present study aimed at scrutinizing the relationship between CS use and L2 learners' proficiency level by pursuing the following research questions:

1. What types of communication strategies (CSs) do EFL learners at the preintermediate, intermediate and advanced levels of proficiency use in order to achieve their communicative goals?

2. How frequently are the different types of CSs applied by each proficiency group? 


\subsection{Participants}

Thirty EFL learners, 15 men and 15 women, between 15 and 34 years old, participated in the study. They were all native speakers of Portuguese and were selected from three different proficiency levels (pre-intermediate, intermediate and advanced) from an extra-curricular foreign-language course at the Regional University of Blumenau-SC, Brazil. It was an initial concern of the present researcher to select each group of participants from the same classroom so as to make sure the amount and quality of L2 input was the same for all learners in their respective proficiency groups. However, because the pre-intermediate groups were composed of few students, 2 classrooms were necessary to put together the 10 participants of this level.

\subsection{Data collection and analysis}

Data collection was carried out within a period corresponding to one academic semester. Learners' L2 oral production was elicited by three different tasks, conducted at a one-month intervals from each other. In the first task, learners were asked to tell a fact in their lives that made them happy. For the second task, learners were supposed to tell the story of a movie they had seen and whether they had liked it. Finally, in the third task, participants were invited to tell the story portrayed in a sequence of pictures of a comic book (FORTKAMP, 1999). Participants had 5 minutes maximum to complete each task, and no kind of interaction was allowed between the participant and the researcher. These procedures were adopted to avoid the use of certain CSs to the detriment of others. The narrative tasks were selected because, as assumed by Lennon (1990), narratives are a usual modality of spoken language, being familiar to most language users. No kind of training was given to participants on how to perform a story-telling task nor were they given time to plan what to say before actually performing the tasks. In the beginning of each data collection session, the researcher would start a conversation with the participant, addressing some questions related to the topic of the task itself. This was done in order to make participants feel more comfortable, self-confident and relaxed to speak.

Aiming at answering the research questions pursued by the present study, data were analysed and classified according to Dörnyei and Kormos's (1998) taxonomy (see Appendix I for a description of all categories of the taxonomy). 
This taxonomy was adopted because it seemed to gather the most common categories of strategies proposed by the literature on CS and also made a link between the use of strategies and speech production processes in L1 and in L2 (see LEVELT, 1989 for monolingual speech production, and POULISSE, 1997 for a review of bilingual speech production models). I turn now to the report and discussion of the results.

\section{Results and Discussion}

\subsection{Types and frequency of use of CSs across proficiency levels}

\subsubsection{The pre-intermediate group}

TABLE 1

Types and frequency of use of CSs in the Pre-Intermediate group - session 1

\begin{tabular}{|c|c|c|c|c|c|c|c|c|c|c|c|}
\hline \multirow[b]{2}{*}{ Types of CS } & \multicolumn{10}{|c|}{ Participants } & \multirow{2}{*}{$\begin{array}{r}\begin{array}{r}\text { Frequency } \\
\text { of CS use }\end{array} \\
\end{array}$} \\
\hline & 1 & 2 & 5 & 6 & 12 & 13 & 14 & 16 & 17 & 33 & \\
\hline Message abandonment & & 1 & 1 & & & & & 1 & 2 & & 5 \\
\hline Message reduction & & & 1 & & & & & & & & 1 \\
\hline Message replacement & & & & & & & & & 1 & & 1 \\
\hline Code-switching & & & & 1 & 5 & 4 & 1 & 2 & 1 & 1 & 15 \\
\hline Approximation & & & 1 & & & & & & & & 1 \\
\hline All-purpose-words & & & & & & & & & & & \\
\hline Complete omission & & & & 2 & & & & & & & 2 \\
\hline Foreignizing & & & 2 & 2 & 1 & & & & 3 & & 8 \\
\hline $\begin{array}{l}\text { Grammatical word } \\
\text { coinage }\end{array}$ & & & & & & & & & & & \\
\hline Literal translation & & & & & & & & & & & \\
\hline Circumlocution & & & & & & & & & & & \\
\hline Semantic word coinage & & & & & & & & & & & \\
\hline Restructuring & & 3 & 1 & & 1 & 1 & & 1 & 2 & 3 & 12 \\
\hline Direct appeal & & & & & & & 1 & & & & 1 \\
\hline Indirect Appeal & & & & & & & & 2 & & & 2 \\
\hline
\end{tabular}


(continuação)

\begin{tabular}{|c|c|c|c|c|c|c|c|c|c|c|c|}
\hline \multirow[b]{2}{*}{ Types of CS } & \multicolumn{10}{|c|}{ Participants } & \multirow{2}{*}{$\begin{array}{r}\text { Frequency } \\
\text { of CS use } \\
\end{array}$} \\
\hline & 1 & 2 & 5 & 6 & 12 & 13 & 14 & 16 & 17 & 33 & \\
\hline Overgeneralization & & 1 & & & 2 & & 4 & & 3 & 4 & 14 \\
\hline Transfer & 1 & 2 & 2 & 5 & 1 & 3 & 3 & 2 & 6 & 1 & 26 \\
\hline Grammatical Reduction & 5 & 10 & 16 & 13 & 10 & 7 & 6 & 5 & 7 & 12 & 91 \\
\hline Phonological Retrieval & & 1 & 2 & 2 & 2 & & 1 & & 2 & 1 & 11 \\
\hline Phonological Substitution & & & & & & & & & 2 & & 2 \\
\hline $\begin{array}{l}\text { Phonological Reduction } \\
\text { (mumbling) }\end{array}$ & & & & & & & & & & 1 & 1 \\
\hline Filled pauses (fillers) & & & 2 & & & & & 1 & 3 & & 6 \\
\hline Unfilled pauses & 17 & 22 & 28 & 15 & 6 & 15 & 25 & 24 & 8 & 11 & 171 \\
\hline Umming and erring & 2 & 16 & 11 & 38 & 13 & 8 & 16 & 3 & 10 & 14 & 131 \\
\hline Lengthening a sound & 6 & 7 & 24 & 18 & 7 & 6 & 12 & 4 & 35 & 20 & 139 \\
\hline Self-repetitions & 3 & 2 & 23 & 23 & 3 & 1 & 10 & 5 & 14 & 23 & 127 \\
\hline Error repair & 1 & 3 & 2 & 1 & 2 & 1 & & 1 & 5 & 6 & 22 \\
\hline $\begin{array}{l}\text { Appropriacy repair } \\
\text { Different repair } \\
\text { Rephrasing repair } \\
\text { Own-accuracy checks }\end{array}$ & & & & 1 & & & 1 & & 1 & & 3 \\
\hline $\begin{array}{l}\text { Total number of CS } \\
\text { per participant }\end{array}$ & 36 & 87 & 116 & 123 & 51 & 46 & 80 & 51 & 105 & 97 & \\
\hline $\begin{array}{l}\text { Total number of } \\
\text { different types of CS } \\
\text { per participant }\end{array}$ & 8 & 10 & 14 & 13 & 11 & 9 & 11 & 12 & 17 & 12 & \\
\hline
\end{tabular}

As can be seen in Table 1, the number of communication strategies used by pre-intermediate participants in session 1 ranged from 36 to 123 . In total, 23 different types of strategies were used by pre-intermediate learners. Six CSs were used by all pre-intermediate participants: transfer, grammatical reduction, unfilled pauses, umming and erring, lengthening a sound and self-repetitions. This might be an indication that pre-intermediate learners still lack enough knowledge to use more sophisticated strategies. It is also interesting to note that six types of strategies were used each, by a different participant: message reduction was used once by participant 5 , only; message replacement was used only once by 
participant 17, only; approximation was also used only once by participant 5; complete omission was used twice by participant 6 ; direct appeal, in which the speaker asks an explicit question of the interlocutor about something he does not know or is in doubt about was used of twice by participant 16; and phonological reduction was used only once by participant 33 . This might indicate that less experienced language users are not aware of the fact that they can use the linguistic resources they have available to convey their messages. Therefore, it is likely that they will focus on the use of those strategies that seem more familiar to them. In sum, the strategies most frequently used by participants were grammatical reduction, unfilled pauses, umming and erring, lengthening a sound and self-repetitions

Taking into consideration the nature of some CSs, it is interesting to note that Pre-Intermediate learners were able to apply the strategies of restructuring and error repair. The first is considered to involve the change of more than one cluster of the preverbal message (POULISSE, 1993). However, it is indeed questionable how the process of clustening occurs in the production of speech and also how many clusters are necessary to classify a CS under this label. According to Dörnyei and Kormos (1998), restructuring is not just a matter of retrieving different lexical entries in order to convey the intended message by an alternative plan. Rather, the process of restructuring seems to involve analysis and decomposition of the message, so that the speaker is able to recombine concepts and lexical items in a more effective manner by using his/her available resources.

The second strategy, error repair, usually occurs when accidental lapses in speech are corrected (DÖRNYEI and KORMOS, 1998). As explained by Dörnyei and Kormos, these lapses can occur during grammatical and phonological encoding as well as during articulation. Monitoring of the language output, in turn, can occur before and after speech is articulated. Monitoring is done by the parser ${ }^{2}$ (LEVELT, 1989), who is in charge of perceiving the accidental lapse in the language outcome and signaling it to the conceptualizer, who, in turn, reruns the preverbal plan by making no modifications in the communicative intention. In this case, the production processes are triggered again, so that an error-free output can be processed (DÖRNYEI and KORMOS, 1998). Hence, in order for preintermediate learners to produce self-corrections of this kind, it is necessary for them to have a certain degree of metalinguistic awareness. Awareness would enable learners to notice the accidental lapses in their speech and correct them - usually, a feature of more proficient learners. 
The same explanation may apply to the use of appropriacy repairs, despite the fact that this type of repair implies modifications in the preverbal plan, since it occurs when the speaker believes he/she encoded inadequate information and decides to change it (DÖRNYEI and KORMOS, 1998). In appropriacy repairs, no lexical, grammatical or phonological problems are apparent, however speakers might choose to repair what they are saying by looking for the most appropriate manner to convey their message.

As mentioned already it is noteworthy that the CSs of transfer, grammatical reduction, unfilled pauses, umming and erring, lengthening and self-repetitions, besides having been employed by all participants, were used many times during learners' speech performance. The relatively high frequency use of CSs by preintermediate learners may be due to their proficiency level, which would foster a greater use of CSs, since learners' at this stage of IL development seem to lack the ideal linguistic knowledge to convey their intended messages without experiencing some language breakdowns. A consequence of this "limited" linguistic knowledge is that learners tend to use simplified grammar when communicating, besides filling their speech with many silent pauses, nonlexicalized fillers, drawls and transfer of $\mathrm{L} 1$ features to $\mathrm{L} 2$ contexts.

TABLE2

Types and frequency of use of CSs in the Pre-Intermediate group - session 2

\begin{tabular}{|c|c|c|c|c|c|c|c|c|c|c|c|}
\hline \multirow[b]{2}{*}{ Types of CS } & \multicolumn{10}{|c|}{ Participants } & \multirow{2}{*}{$\begin{array}{r}\begin{array}{r}\text { Frequency } \\
\text { of CS use }\end{array} \\
\end{array}$} \\
\hline & $\mathbf{1}$ & 2 & 5 & 6 & 12 & 13 & 14 & 16 & 17 & 33 & \\
\hline Message abandonment & & 1 & 1 & 1 & 1 & 2 & & 1 & 1 & & 8 \\
\hline Message reduction & & & & & 3 & & & & & & 3 \\
\hline Message replacement & & & & & 2 & & 1 & 1 & & & 4 \\
\hline Code-switching & & & & 2 & 12 & 15 & 1 & 4 & & & 34 \\
\hline Approximation & & & & & & & & & & & \\
\hline All-purpose-words & & & & & & & 1 & & & & 1 \\
\hline Complete omission & & & 2 & 1 & 1 & & 1 & 1 & & 1 & 7 \\
\hline Foreignizing & & & & & & 1 & & 14 & & 1 & 16 \\
\hline $\begin{array}{l}\text { Grammatical word } \\
\text { coinage }\end{array}$ & & & & & & & & & & & \\
\hline
\end{tabular}


(continuação)

\begin{tabular}{|c|c|c|c|c|c|c|c|c|c|c|c|}
\hline \multirow[b]{2}{*}{ Types of CS } & \multicolumn{10}{|c|}{ Participants } & \multirow{2}{*}{$\begin{array}{l}\text { Frequency } \\
\text { of CS use }\end{array}$} \\
\hline & 1 & 2 & 5 & 6 & 12 & 13 & 14 & 16 & 17 & 33 & \\
\hline \multirow{3}{*}{\multicolumn{12}{|c|}{$\begin{array}{l}\text { Literal translation } \\
\text { Circumlocution } \\
\text { Semantic word coinage }\end{array}$}} \\
\hline & & & & & & & & & & & \\
\hline & & & & & & & & & & & \\
\hline Restructuring & & & 1 & 1 & & 1 & 1 & 1 & & 1 & 6 \\
\hline Direct appeal & & & & & & & & 1 & & & 1 \\
\hline Indirect Appeal & & & & 3 & & & & & & & 3 \\
\hline Overgeneralization & 1 & 1 & & & 2 & & & 1 & & 1 & 6 \\
\hline Transfer & 5 & 1 & 1 & 4 & 3 & 3 & 4 & 5 & 8 & 3 & 37 \\
\hline Grammatical Reduction & 3 & 6 & 4 & 8 & 13 & 13 & 7 & 8 & 3 & 18 & 83 \\
\hline Phonological Retrieval & 1 & 1 & 1 & 4 & 2 & 1 & 1 & 3 & 2 & 1 & 17 \\
\hline Phonological Substitution & & & 1 & 1 & & & & & & & 2 \\
\hline $\begin{array}{l}\text { Phonological Reduction } \\
\text { (mumbling) }\end{array}$ & & & 3 & & 1 & 1 & 1 & 1 & & & 7 \\
\hline Filled pauses (fillers) & & 3 & & 11 & 3 & & & 1 & & & 18 \\
\hline Unfilled pauses & 9 & 4 & 13 & 18 & 18 & 11 & 15 & 19 & 15 & 3 & 125 \\
\hline Umming and erring & 4 & 21 & 16 & 26 & 34 & 27 & 31 & 10 & 14 & 16 & 199 \\
\hline Lengthening a sound & 10 & 3 & 15 & 16 & 22 & 16 & 14 & 18 & 19 & 26 & 159 \\
\hline Self-repetitions & 3 & 3 & 23 & 17 & 3 & 3 & 10 & 18 & 12 & 12 & 104 \\
\hline Error repair & 2 & 4 & 2 & & 5 & 7 & 1 & 3 & 4 & 6 & 34 \\
\hline Appropriacy repair & & & 1 & 1 & 1 & & & & & 2 & 5 \\
\hline Different repair & 1 & & & & & & & & & & 1 \\
\hline Rephrasing repair & & & & & & & & & & & \\
\hline Own-accuracy checks & & & & & & 1 & & & & & 1 \\
\hline $\begin{array}{l}\text { Total number of CS } \\
\text { per participant }\end{array}$ & 39 & 48 & 84 & 114 & 126 & 102 & 89 & 110 & 78 & 91 & \\
\hline $\begin{array}{l}\text { Total number of } \\
\text { different types of CS } \\
\text { per participant }\end{array}$ & 10 & 11 & 14 & 15 & 17 & 14 & 14 & 18 & 10 & 13 & \\
\hline
\end{tabular}

As can bee seen in Table 2 above, the number of communication strategies used by pre-intermediate participants in session 2 ranged from 39 to 126 . To summarize, 25 different types of strategies comprising lexical, grammatical, 
phonological and process time pressure problems were used by pre-intermediate learners. Likewise, session 1, 7 CSs were used by all pre-intermediate participants in session 2: transfer, grammatical reduction, phonological retrieval, unfilled pauses, umming and erring, lengthening a sound and self-repetitions. It is also worth highlighting that six types of strategies were used each, by a different learner: message reduction - used three times by participant 12; all-purpose-words - used once by participant 14; direct appeal - used once by participant 16; indirect appeal - used three times by participant 6 ; different repair - used once by participant 1 , and self-accuracy check - used only once by participant 13 . The strategies most often applied by pre-intermediate participants, in session 2 , were grammatical reduction, unfilled pauses, umming and erring, lengthening a sound and self-repetitions, followed by transfer, error-repair and code-switching.

TABLE 3

Types and frequency of use of CSs in the Pre-Intermediate group - session 3

\begin{tabular}{|c|c|c|c|c|c|c|c|c|c|c|c|}
\hline \multirow[b]{2}{*}{ Types of CS } & \multicolumn{10}{|c|}{ Participants } & \multirow{2}{*}{$\begin{array}{r}\text { Frequency } \\
\text { of CS use }\end{array}$} \\
\hline & 1 & 2 & 5 & 6 & 12 & 13 & 14 & 16 & 17 & 33 & \\
\hline Message abandonment & & & & 1 & & 1 & 1 & 1 & 3 & & 7 \\
\hline Message reduction & & & & 1 & & & & 1 & & & 2 \\
\hline Message replacement & & 2 & 3 & & & & & 1 & & & 6 \\
\hline Code-switching & & & & 4 & 12 & 5 & 3 & 6 & & 1 & 31 \\
\hline Approximation & & 2 & 1 & 3 & 4 & 1 & & 1 & 1 & 4 & 17 \\
\hline All-purpose-words & & & 1 & & & & & & & & 1 \\
\hline Complete omission & & & & & 6 & & 3 & & & 1 & 10 \\
\hline Foreignizing & & & & & & 1 & & 2 & 1 & & 4 \\
\hline $\begin{array}{l}\text { Grammatical word } \\
\text { coinage }\end{array}$ & & 2 & & & & & & & & & 2 \\
\hline Literal translation & & & & & & & & 1 & 3 & & 4 \\
\hline Circumlocution & & & & & & & & & 2 & & 2 \\
\hline $\begin{array}{l}\text { Semantic word coinage } \\
\text { Restructuring }\end{array}$ & & & & & & 2 & & & & & 2 \\
\hline Direct Appeal & & & & & 1 & & & 1 & & & 2 \\
\hline Indirect Appeal & & & & 2 & & & & & & & 2 \\
\hline Overgeneralization & & 1 & & & & & 1 & & & & 2 \\
\hline
\end{tabular}


(continuação)

\begin{tabular}{|c|c|c|c|c|c|c|c|c|c|c|c|}
\hline \multirow[b]{2}{*}{ Types of CS } & \multicolumn{10}{|c|}{ Participants } & \multirow{2}{*}{$\begin{array}{l}\text { Frequency } \\
\text { of CS use }\end{array}$} \\
\hline & $\mathbf{1}$ & 2 & 5 & 6 & 12 & 13 & 14 & 16 & 17 & 33 & \\
\hline Transfer & 1 & 1 & 5 & 5 & 11 & 4 & 3 & 2 & 3 & 6 & 41 \\
\hline Grammatical Reduction & 4 & 9 & 8 & 16 & 10 & 8 & 7 & 8 & 3 & 3 & 76 \\
\hline Phonological Retrieval & 1 & & & 2 & 2 & 1 & 1 & 1 & & 1 & 9 \\
\hline Phonological Substitution & & & & & & & & & 2 & & 2 \\
\hline $\begin{array}{l}\text { Phonological Reduction } \\
\text { (mumbling) }\end{array}$ & 1 & & 2 & & & & & & & 1 & 4 \\
\hline Filled pauses (fillers) & & & 1 & 8 & 5 & 1 & & & 1 & 1 & 17 \\
\hline Unfilled pauses & 22 & 20 & 29 & 17 & 10 & 12 & 21 & 18 & 14 & 8 & 171 \\
\hline Umming and erring & 1 & 10 & 15 & 30 & 34 & 13 & 12 & 10 & 14 & 10 & 149 \\
\hline Lengthening a sound & 8 & 13 & 22 & 21 & 22 & 9 & 11 & 22 & 25 & 14 & 167 \\
\hline Self-repetitions & 5 & 17 & 16 & 9 & 4 & 6 & 7 & 14 & 12 & 8 & 98 \\
\hline Error repair & 3 & 5 & 2 & 4 & 6 & 3 & 1 & 4 & 1 & 3 & 32 \\
\hline Appropriacy repair & & & & & & & 1 & & 3 & & 4 \\
\hline Different repair & & & & & & & & 1 & & & 1 \\
\hline Rephrasing repair & & & 3 & & & & 1 & 1 & & & 5 \\
\hline Own-accuracy checks & & & & & & & & & & & \\
\hline $\begin{array}{l}\text { Total number of CS } \\
\text { per participant }\end{array}$ & 46 & 82 & 108 & 133 & 123 & 67 & 73 & 96 & 86 & 61 & \\
\hline $\begin{array}{l}\text { Total number of } \\
\text { different types of CS } \\
\text { per participant }\end{array}$ & 9 & 11 & 13 & 16 & 14 & 14 & 14 & 19 & 14 & 13 & \\
\hline
\end{tabular}

According to Table 3 , the number of communication strategies used by pre-intermediate participants in session 3 ranged from 46 to 133. In total, 29 different types of strategies comprising lexical, grammatical, phonological and process time pressure problems were used by pre-intermediate learners. It is important to point out that $7 \mathrm{CSs}$ were used by all pre-intermediate participants in session 3: transfer, grammatical reduction, unfilled pauses, umming and erring, lengthening a sound, self-repetitions, and error-repair. In addition, six types of strategies were used, each, by a different learner: all-purpose-words, which consists of using general terms to replace the unknown lexical item, such as things, do, and make, was used once by participant 5; grammatical word coinage, 
in which the speaker creates a nonexisting L2 based on a supposed L2 rule, was used twice by participant 2 ; circumlocution, in which the speaker describes the characteristics of the lexical item instead of saying it, was used twice by participant 17; restructuring, which consists of abandoning part of the message and trying to convey it using another way, was used twice by participant 13; indirect appeal was used twice by participant 6 ; and different repair, in which the speaker decided to change the message by encoding different information, was used only once by participant 16 . Grammatical reduction, unfilled pauses, umming and erring, lengthening a sound, and self-repetitions were the strategies most often applied by pre-intermediate participants in this session.

To sum up, in the pre-intermediate group, there seems to be a tendency for the use of some CSs across sessions. Except for phonological retrieval, the CSs of transfer, grammatical reduction, unfilled pauses, umming and urring, lengthening and self-repetitions appear to be the most used strategies across sessions 1,2 and 3 . These strategies were not only applied by all participants, but were also frequently used by them.

As can be observed in Tables 1,2 and 3, in the pre-intermediate group, speakers who applied more CSs in general also presented a greater number of different strategy types. For instance, in session 1, participant 5 applied CSs 116 times and 14 different types of strategies; participant 6 used CSs 123 times and 13 different types; participant 17 used CSs 105 times and 17 kinds of strategies and participant 33 resorted to $97 \mathrm{CSs}$, which corresponds to 12 different types. Despite not applying so many CSs in comparison to the others (only 51), participant 16 presented 12 different types of CSs as well.

Similarly, in sessions 2 and 3, most of the participants who used a high number of CSs also presented a greater number of different types of strategies. For example, in session 2, participant 6 used CSs 114 times and 15 different types of strategies; participant 12 used 123 CSs and 17 different types; participant 13 applied 105 CSs and 14 kinds of strategies and participant 16 used CSs 99 times and 18 different types of strategies. In session 3 , a similar situation occurs with participant 6 who resorted to CSs 133 times, which corresponds to 16 different kinds of strategies; participant 12 who used 123 CSs and 14 different types, and participant 16 who used $96 \mathrm{CSs}$ and 19 different types of strategies. The analysis of the number of different strategy types used by pre-intermediate learners across sessions shows that at this level of interlanguage development, these learners seem to resort to a relatively high number of different types of strategies. 


\subsubsection{The intermediate group}

TABLE 4

Types and frequency of use of CSs in the Intermediate group - session 1

\begin{tabular}{|c|c|c|c|c|c|c|c|c|c|c|c|}
\hline \multirow[b]{2}{*}{ Types of CS } & \multicolumn{10}{|c|}{ Participants } & \multirow{2}{*}{$\begin{array}{c}\text { Frequency } \\
\text { of CS use }\end{array}$} \\
\hline & 22 & 23 & 24 & 25 & 26 & 27 & 28 & 29 & 31 & 32 & \\
\hline Message abandonment & & 1 & & 1 & 3 & 1 & 1 & 1 & 1 & 1 & 10 \\
\hline Message reduction & & & & & 2 & & 1 & & & & 3 \\
\hline Message replacement & & & & & 1 & & & 1 & & & 2 \\
\hline Code-switching & & 1 & & 10 & & & & & 3 & 2 & 16 \\
\hline Approximation & & & & & 1 & & & 1 & & 1 & 3 \\
\hline All-purpose-words & & & 1 & & 2 & & 3 & 4 & & 1 & 11 \\
\hline Complete omission & & & & & & & 2 & 4 & & 1 & 7 \\
\hline Foreignizing & & & & 1 & 4 & 1 & 1 & 2 & & & 9 \\
\hline $\begin{array}{l}\text { Grammatical word } \\
\text { coinage }\end{array}$ & & & & 1 & & & & & & & 1 \\
\hline Literal translation & & & 1 & & & & & & & & 1 \\
\hline Circumlocution & & & & & & & & & 1 & & 1 \\
\hline $\begin{array}{l}\text { Semantic word coinage } \\
\text { Restructuring }\end{array}$ & 2 & 1 & 1 & 3 & 2 & & 1 & 1 & & & 11 \\
\hline Direct appeal & & 1 & & & & 1 & & & & & 2 \\
\hline Indirect Appeal & & & & 2 & 1 & & & & 1 & & 4 \\
\hline Overgeneralization & 1 & 1 & 1 & 1 & & & & & 1 & & 5 \\
\hline Transfer & 1 & 2 & 12 & 8 & 6 & 5 & 5 & 1 & 4 & 5 & 49 \\
\hline Grammatical Reduction & 9 & 12 & 15 & 26 & 20 & 27 & 13 & 26 & 12 & 29 & 189 \\
\hline $\begin{array}{l}\text { Phonological Retrieval } \\
\text { Phonological Substitution }\end{array}$ & 1 & 2 & & 4 & 2 & & 4 & 6 & 4 & 2 & 24 \\
\hline $\begin{array}{l}\text { Phonological Reduction } \\
\text { (mumbling) }\end{array}$ & & & 1 & & & & & & & & 1 \\
\hline Filled pauses (fillers) & & & 5 & 6 & 2 & & & & 4 & 28 & 45 \\
\hline Unfilled pauses & 22 & 16 & 24 & 11 & 7 & 22 & 5 & 24 & 9 & 17 & 157 \\
\hline Umming and erring & 17 & 24 & 6 & 29 & 29 & 10 & 22 & 8 & 17 & 14 & 176 \\
\hline Lengthening a sound & 16 & 5 & 10 & 16 & 13 & 13 & 33 & 10 & 56 & 11 & 183 \\
\hline Self-repetitions & 19 & 25 & 4 & 60 & 22 & 14 & 23 & 26 & 29 & 26 & 248 \\
\hline
\end{tabular}


(continuação)

\begin{tabular}{|c|c|c|c|c|c|c|c|c|c|c|c|}
\hline \multirow[b]{2}{*}{ Types of CS } & \multicolumn{10}{|c|}{ Participants } & \multirow{2}{*}{$\begin{array}{l}\text { Frequency } \\
\text { of CS use }\end{array}$} \\
\hline & 22 & 23 & 24 & 25 & 26 & 27 & 28 & 29 & 31 & 32 & \\
\hline Error repair & 6 & 4 & 1 & 10 & 2 & 2 & & 1 & 3 & 5 & 34 \\
\hline Appropriacy repair & & & & 2 & 1 & 3 & 5 & 4 & & 2 & 17 \\
\hline Different repair & & & & & & & & & & & \\
\hline Rephrasing repair & 2 & 2 & & 4 & 2 & 2 & & 2 & 1 & 3 & 18 \\
\hline Own-accuracy checks & & & & & & & & & & & \\
\hline $\begin{array}{l}\text { Total number of CS } \\
\text { per participant }\end{array}$ & 96 & 96 & 82 & 196 & 122 & 101 & 119 & 122 & 146 & 147 & \\
\hline $\begin{array}{l}\text { Total number of } \\
\text { different types of CS } \\
\text { per participant }\end{array}$ & 11 & 13 & 13 & 19 & 19 & 12 & 14 & 17 & 15 & 16 & \\
\hline
\end{tabular}

Table 4 displays the types and frequency of use of CSs found and the speech of intermediate learners in session 1 . As can be observed, the number of communication strategies used by these participants in this session ranged from 82 to 196. In total, 27 different types of strategies comprising lexical, grammatical, phonological and process time pressure problems were used by intermediate learners. Six CSs were used by all intermediate participants in session 1: transfer, grammatical reduction, unfilled pauses, umming and erring, lengthening a sound and self-repetitions. It is also worth pointing out that only three types of strategies were used, once each, by a different learner: literal translation was used once by participant 24 ; circumlocution was used once by participant 31 , and phonological reduction was used once by participant 24 . The strategies most often applied by intermediate participants in session 1 are the same applied by the pre-intermediate group across the three sessions: grammatical reduction, unfilled pauses, umming and erring, lengthening a sound and self-repetitions.

In addition, intermediate learners seem to be very concerned with the quality of their messages, since the total number of self-corrections (error-repair, appropriacy repair, different repair, and rephrasing repair) increased in comparison to pre-intermediate learners. The pre-intermediate group produced 107 self-repairs across the 3 sessions, whereas the intermediate surpassed this score by applying a total of 196 self-corrections. Only in session 1, did intermediate learners selfcorrect 69 times. Most of these repairs were error-repairs, which may indicate 
that learners seem to improve their capacity to think about language and monitor their own speech as their IL system develops.

Rephrasing repair was also a CS fairly used by intermediate learners. On the one hand, this might demonstrate their concern with making their message understandable to their interlocutor; that is, making themselves clear. On the other, the use of rephrasing repair may be triggered by speakers' uncertainty about the correctness of what was said (due to grammatical, lexical, phonological or time constraints). Thus, in order to be sure the message will be conveyed successfully, the speaker repeats a slightly modified version of the utterance previously produced. According to Dörnyei and Kormos (1998), this modified version does not require changes in the macroplanning (where the communicative goals are conceptualized), since the intention is the same with just small changes in the encoding process.

Despite presenting a low frequency of use, the CS of message abandonment (when the speaker abandons the message because of lack of linguistic resources) was applied more times by intermediate than by pre-intermediate learners, especially in sessions 1 and 2. However, it was expected that the number of message abandonment should decrease across proficiency levels, since learners go on acquiring more experience as language users. A more proficient learner with a more developed IL system might be able to overcome communicative problems more easily without giving up the communicative goal. Thus, the fact that intermediate learners showed more instances of message abandonment may indicate that they prefer to reduce the message so as to avoid problems and the risk of not being understood.

Lexicalized pauses or fillers - well, you know, ok - were also employed by the intermediate group, especially by participant 32 in session 1 ( 28 instances). According to Dörnyei and Kormos (1998), these fillers are chunks of formulaic language used by $\mathrm{L} 2$ speakers to gain more time to produce speech, since some parts of the language production process in L2 speakers run serially (LEVELT, 1989). This limitation requires from $L 2$ language users more time to process what to say and may cause speech to seem unfluent and produce a great amount of silent periods or hesitations.

Another CS used by 8 out of 10 participants in session 1 was phonological retrieval, whereby speakers try to retrieve and articulate a lexeme (phonological feature of the lexical item) for which he/she is not sure. The speaker keeps uttering different phonological versions of the item, till the best one is selected (DÖRNYEI and KORMOS, 1998). Literature in the area of CSs also names this 
process as a slip of the tongue. The 24 instances classified in the first session may indicate learners' desire of saying the right word with the right pronunciation.

TABLE 5

Types and frequency of use of CSs in the Intermediate group - session 2

\begin{tabular}{|c|c|c|c|c|c|c|c|c|c|c|c|}
\hline \multirow[b]{2}{*}{ Types of CS } & \multicolumn{10}{|c|}{ Participants } & \multirow{2}{*}{$\begin{array}{r}\text { Frequency } \\
\text { of CS use }\end{array}$} \\
\hline & 22 & 23 & 24 & 25 & 26 & 27 & 28 & 29 & 31 & 32 & \\
\hline Message abandonment & & 1 & & 2 & 4 & & & & 1 & 3 & 11 \\
\hline Message reduction & & & & & & 1 & & 1 & & & 2 \\
\hline Message replacement & & & & & & & & & & & \\
\hline Code-switching & 1 & 2 & & 2 & 10 & 1 & 1 & & 3 & 1 & 21 \\
\hline Approximation & & 3 & & 1 & 3 & 1 & & & & & 8 \\
\hline All-purpose-words & & & & & & & & & & & \\
\hline Complete omission & & & 2 & 1 & 1 & 2 & 1 & 3 & 1 & 2 & 13 \\
\hline Foreignizing & & & 1 & & 2 & 1 & & & & 2 & 6 \\
\hline $\begin{array}{l}\text { Grammatical word } \\
\text { coinage }\end{array}$ & & 2 & 1 & 1 & & & & & & & 4 \\
\hline Literal translation & 1 & 1 & & 3 & & & & & & & 5 \\
\hline Circumlocution & & & & & & & & & & & \\
\hline Semantic word coinage & & & & & & & & & & & \\
\hline Restructuring & & & & 1 & 2 & 1 & 2 & & 1 & & 7 \\
\hline Direct appeal & & 2 & & & & & & & & & 2 \\
\hline Indirect Appeal & & & & 1 & 3 & & & & & 1 & 5 \\
\hline Overgeneralization & 3 & 1 & & 3 & 2 & & 1 & & 2 & & 12 \\
\hline Transfer & 1 & 1 & 4 & 1 & 9 & 5 & 4 & 8 & 5 & 7 & 45 \\
\hline Grammatical Reduction & 9 & 14 & 6 & 8 & 15 & 20 & 15 & 13 & 5 & 22 & 127 \\
\hline Phonological Retrieval & 3 & 5 & 1 & 5 & 2 & 1 & 2 & 5 & 4 & 8 & 36 \\
\hline Phonological Substitution & & & 1 & & & & & & & & 1 \\
\hline $\begin{array}{l}\text { Phonological Reduction } \\
\text { (mumbling) }\end{array}$ & & 3 & & & 2 & & & & & & 5 \\
\hline Filled pauses (fillers) & & & & 3 & 1 & & & & & 22 & 26 \\
\hline Unfilled pauses & 15 & 11 & 22 & 15 & 16 & 37 & 12 & 26 & 13 & 20 & 187 \\
\hline Umming and erring & 18 & 40 & 4 & 14 & 41 & 9 & 17 & 5 & 17 & 24 & 189 \\
\hline Lengthening a sound & 27 & 23 & 20 & 14 & 21 & 19 & 43 & 10 & 27 & 26 & 230 \\
\hline
\end{tabular}

(continua) 
(continuação)

\begin{tabular}{|c|c|c|c|c|c|c|c|c|c|c|c|}
\hline \multirow[b]{2}{*}{ Types of CS } & \multicolumn{10}{|c|}{ Participants } & \multirow{2}{*}{$\begin{array}{r}\text { Frequency } \\
\text { of CS use }\end{array}$} \\
\hline & 22 & 23 & 24 & 25 & 26 & 27 & 28 & 29 & 31 & 32 & \\
\hline Self-repetitions & 26 & 38 & 4 & 20 & 30 & 12 & 16 & 14 & 13 & 19 & 192 \\
\hline Error repair & 5 & 2 & 2 & 2 & 5 & 2 & 3 & 2 & 3 & 2 & 28 \\
\hline Appropriacy repair & 1 & 2 & 2 & 1 & 3 & 11 & 1 & 1 & 1 & 4 & 27 \\
\hline Different repair & & & & & & & 1 & & & 2 & 3 \\
\hline $\begin{array}{l}\text { Rephrasing repair } \\
\text { Own-accuracy checks }\end{array}$ & 3 & & 2 & 2 & 7 & 3 & 1 & 1 & & 5 & 24 \\
\hline $\begin{array}{l}\text { Total number of CS } \\
\text { per participant }\end{array}$ & 113 & 151 & 72 & 100 & 179 & 126 & 120 & 89 & 96 & 170 & \\
\hline $\begin{array}{l}\text { Total number of } \\
\text { different types of CS } \\
\text { per participant }\end{array}$ & 13 & 17 & 14 & 20 & 20 & 16 & 15 & 12 & 14 & 17 & \\
\hline
\end{tabular}

As displayed by Table 5, in session 2, the number of communication strategies used by intermediate participants ranged from 72 to 179. In total, 26 different types of strategies were used by intermediate participants. Nine different types of strategies were used by all intermediate participants: transfer, grammatical reduction, phonological retrieval, unfilled pauses, umming and erring, lengthening a sound, self-repetitions, error repair, and appropriacy repair. This might be an indication that intermediate learners possess a larger repertoire of CSs, since they also have a more extended knowledge of the language at this stage of interlanguage development. Moreover, although with a lower frequency, the CSs of code switching and approximation were also applied by intermediate learners in both sessions, 1 and 2 . In the case of code switching, the intermediate group produced less of this strategy than the pre-intermediate group. This result seems to be in accordance with the different proficiency levels of the participants and their language competence. However, approximation was more frequent in the intermediate group, which might indicate that intermediate speakers handle their linguistic resources more effectively than pre-intermediate ones when communicating. This is because approximation may be considered a more sophisticated strategy, since learners need to have more knowledge about the language; particularly about lexical items' relations and to what part of speech they belong, such as nouns, verbs, adjectives, and articles, in order to apply this 
CS. It is also interesting to note that only two types of strategies were used, each, by a different participant: direct appeal was used twice by participant 23 , and phonological substitution was used once by participant 24 .

Interestingly, there seems to be a pattern in the use of CSs in session 1 and in session 2. The CSs of transfer, grammatical reduction, unfilled pauses, umming and erring, lengthening and self-repetitions appear to form a common set of strategies in the repertoire of intermediate speakers, not only because they were applied in both sessions, but also because their frequency use was relatively high and because they were employed by the majority of the participants.

Finally, as shown by Table 6, in session 3, the number of communication strategies used by intermediate participants ranged from 38 to 105 . In total, 27 different types of strategies were used by intermediate learners in this session. The most employed strategies were grammatical reduction, unfilled pauses, umming and erring, lengthening a sound, self-repetitions and error repair, with 99, $116,119,136,122$ and 54 uses, respectively.

TABLE 6

Types and frequency of use of CSs in the Intermediate group - session 3

\begin{tabular}{|c|c|c|c|c|c|c|c|c|c|c|c|}
\hline \multirow[b]{2}{*}{ Types of CS } & \multicolumn{10}{|c|}{ Participants } & \multirow{2}{*}{$\begin{array}{r}\begin{array}{r}\text { Frequency } \\
\text { of CS use }\end{array} \\
\end{array}$} \\
\hline & 22 & 23 & 24 & 25 & 26 & 27 & 28 & 29 & 31 & 32 & \\
\hline Message abandonment & & & & 1 & 2 & & & & & 2 & 5 \\
\hline Message reduction & 1 & & & & & & & & & & 1 \\
\hline Message replacement & & & & & & & & & & & \\
\hline Code-switching & & 3 & & 7 & 6 & & 1 & 2 & 3 & 1 & 23 \\
\hline Approximation & 3 & 4 & 1 & 1 & 1 & 1 & 1 & 3 & 3 & & 18 \\
\hline All-purpose-words & & & & & & & & & & & \\
\hline Complete omission & & 3 & & 1 & & & & 1 & & 2 & 7 \\
\hline Foreignizing & & 1 & & & & & 1 & & & & 2 \\
\hline $\begin{array}{l}\text { Grammatical word } \\
\text { coinage }\end{array}$ & & 1 & & & & & & & & & 1 \\
\hline Literal translation & & & & & & 1 & & & & & 1 \\
\hline Circumlocution & & & & & & & & & 1 & & 1 \\
\hline Semantic word coinage & & & & & & & & & & & \\
\hline Restructuring & & & & 1 & 1 & 1 & & & & & 3 \\
\hline
\end{tabular}


(continuação)

\begin{tabular}{|c|c|c|c|c|c|c|c|c|c|c|c|}
\hline \multirow[b]{2}{*}{ Types of CS } & \multicolumn{10}{|c|}{ Participants } & \multirow{2}{*}{$\begin{array}{r}\text { Frequency } \\
\text { of CS use }\end{array}$} \\
\hline & 22 & 23 & 24 & 25 & 26 & 27 & 28 & 29 & 31 & 32 & \\
\hline \multicolumn{12}{|l|}{ Direct Appeal } \\
\hline Indirect Appeal & & & & 2 & 2 & & & 1 & & & 5 \\
\hline Overgeneralization & & & & 1 & & & & & & & 1 \\
\hline Transfer & 1 & 4 & 1 & 8 & 2 & 1 & & 2 & 3 & 1 & 23 \\
\hline Grammatical Reduction & 2 & 12 & 7 & 14 & 6 & 12 & 10 & 15 & 8 & 13 & 99 \\
\hline Phonological Retrieval & & 3 & & & & & 2 & & & & 5 \\
\hline Phonological Substitution & & & & & & & & & & 3 & 3 \\
\hline $\begin{array}{l}\text { Phonological Reduction } \\
\text { (mumbling) }\end{array}$ & & & & & & & 1 & & & & 1 \\
\hline Filled pauses (fillers) & & & 1 & 8 & & & & 1 & 1 & 10 & 21 \\
\hline Unfilled pauses & 23 & 4 & 15 & & 10 & 13 & 13 & 22 & 12 & 4 & 116 \\
\hline Umming and erring & 4 & 32 & 1 & 13 & 20 & 5 & 13 & 8 & 15 & 8 & 119 \\
\hline Lengthening a sound & 13 & 16 & 12 & 11 & 15 & 1 & 32 & 12 & 16 & 8 & 136 \\
\hline Self-repetitions & 20 & 14 & & 2 & 24 & 5 & 15 & 11 & 14 & 17 & 122 \\
\hline Error repair & 4 & 6 & & 29 & 4 & 2 & 5 & 1 & 2 & 1 & 54 \\
\hline Apropriacy repair & 2 & 1 & & 4 & 3 & & & & & 1 & 11 \\
\hline Different repair & 1 & & & 1 & & & 1 & 1 & & & 4 \\
\hline Rephrasing repair & 1 & & & & 1 & & 1 & 1 & & 1 & 5 \\
\hline Own-accuracy checks & & & & 1 & & & & & & & 1 \\
\hline $\begin{array}{l}\text { Total number of CS } \\
\text { per participant }\end{array}$ & 75 & 104 & 38 & 105 & 97 & 42 & 96 & 81 & 74 & 76 & \\
\hline $\begin{array}{l}\text { Total number of } \\
\text { different types of CS } \\
\text { per participant }\end{array}$ & 12 & 14 & 7 & 17 & 14 & 10 & 13 & 14 & 9 & 16 & \\
\hline
\end{tabular}

As can be seen from Tables 4, 5, and 6 above, although participants at this level of proficiency appear to present a larger repertoire of CSs at their disposal, they tended to concentrate on the use of transfer, grammatical reduction, unfilled pauses, umming and erring, lengthening and self-repetitions, all with a high frequency of use, similarly to the pre-intermediate group. However, most participants increased the number of different types of CSs applied across sessions, except for participants 29 and 31 . Concerning participant 29, the total 
number of different kinds of CSs decreased in the second session and increased again in the third one. On the other hand, participant 31 continued decreasing from session 2 to 3 .

Moreover, in session 1, there were participants who used a great number of CSs of many different types, for instance, participant 25. He applied CSs 196 times and used 19 different types. However, there were others who showed a high frequency of CSs use but the types of these strategies did not vary. For instance, participant 31 used CSs 146 times, but presented a relatively smaller repertoire of strategies - 15 - if compared to participant 25 . Conversely, participant 28 employed 119 CSs distributed in 14 different types, that is, fewer CSs and fewer categories.

In session 2 the pattern is similar. Participants who used more CSs during this session, tended to present a larger repertoire of strategies. For instance, participant 23 used CSs 151 times and 17 different types; participant 26 applied 179 CSs of 20 different kinds of strategies; participant 27 used CSs 126 times and 16 types, and participant 32 used CSs 170 times and 17 different types. Conversely, participant 25 can be considered an outlier in the intermediate group - session 2, since he produced fewer CSs, but presented a large repertoire of strategies $-100 \mathrm{CSs}$ and 20 categories.

In session 3, the total number of CSs applied in general was smaller than in session 2 (mean CSs use per participant $=78,7$ ). Participant 25 was the learner who resorted to CSs most frequently - 105 times, and used 17 different types of CSs. Nevertheless, participant 23 applied 104 CS, but presented only 14 categories, similarly to participant 26, who used 96 CSs within 14 types of strategies. On the contrary, participant 32 used fewer CSs -76 and presented a larger repertoire than participant $23-16$ different types.

All in all, these results show that there seems to be a tendency in the use of different types of CSs in the intermediate group: (i) participants who used more CSs also applied more different types of strategies, and (ii) participants who used few CSs also applied strategies from few different types. 


\subsubsection{The advanced group}

TABLE 7

Types and frequency of use of CSs in the Advanced group - session 1

\begin{tabular}{|c|c|c|c|c|c|c|c|c|c|c|c|}
\hline \multirow[b]{2}{*}{ Types of CS } & \multicolumn{10}{|c|}{ Participants } & \multirow{2}{*}{\begin{tabular}{|c|} 
Frequency \\
of CS use
\end{tabular}} \\
\hline & 7 & 8 & 9 & 10 & 11 & 18 & 19 & 20 & 21 & 30 & \\
\hline Message abandonment & 3 & & & & 1 & 1 & 1 & & 1 & & 7 \\
\hline Message reduction & & 1 & & & & & & & & 1 & 2 \\
\hline Message replacement & 1 & 2 & & & & & & & 1 & & 4 \\
\hline Code-switching & & & 1 & & 3 & & & 5 & & & 9 \\
\hline Approximation & 1 & & & 2 & & 2 & & & & & 5 \\
\hline All-purpose-words & & & & 2 & & & & & 1 & & 3 \\
\hline Complete omission & 3 & & & 3 & 2 & 1 & 2 & 1 & & & 12 \\
\hline Foreignizing & & & & & & & 1 & & & & 1 \\
\hline $\begin{array}{l}\text { Grammatical word } \\
\text { coinage }\end{array}$ & & & & & & & & & & 1 & 1 \\
\hline Literal translation & 2 & & & & 1 & & 1 & 1 & & & 5 \\
\hline Circumlocution & & & 1 & 1 & & & 1 & & & & 3 \\
\hline Semantic word coinage & & & & & & & & & & & \\
\hline Restructuring & & 2 & & 2 & 1 & 2 & 4 & 2 & & & 13 \\
\hline Direct appeal & 1 & & & & & & & & & & 1 \\
\hline Indirect Appeal & 1 & & & & 1 & & & & & 1 & 3 \\
\hline Overgeneralization & & 2 & & & & & & 2 & 1 & 1 & 6 \\
\hline Transfer & 4 & 9 & & 2 & 3 & 3 & 12 & 2 & 2 & & 37 \\
\hline Grammatical Reduction & 13 & 13 & 6 & 13 & 19 & 9 & 20 & 20 & 1 & 12 & 126 \\
\hline Phonological Retrieval & 3 & 1 & & 3 & 3 & 1 & 3 & 1 & 4 & 4 & 23 \\
\hline Phonological Substitution & & & & & & & 1 & & & & 1 \\
\hline $\begin{array}{l}\text { Phonological Reduction } \\
\text { (mumbling) }\end{array}$ & & 1 & & & & & & & & 1 & 2 \\
\hline Filled pauses (fillers) & & 1 & & & 1 & 1 & & & & & 3 \\
\hline Unfilled pauses & 19 & 26 & 25 & 15 & 26 & 30 & 39 & 53 & 4 & 37 & 274 \\
\hline Umming and erring & 24 & 12 & & 9 & 25 & 12 & 15 & 9 & 26 & 24 & 156 \\
\hline Lengthening a sound & 40 & 8 & 23 & 24 & 20 & 24 & 28 & 9 & 4 & 40 & 220 \\
\hline Self-repetitions & 15 & 21 & 11 & 14 & 26 & 24 & 32 & 15 & 9 & 13 & 180 \\
\hline
\end{tabular}


(continuação)

\begin{tabular}{|c|c|c|c|c|c|c|c|c|c|c|c|}
\hline \multirow[b]{2}{*}{ Types of CS } & \multicolumn{10}{|c|}{ Participants } & \multirow{2}{*}{\begin{tabular}{|r|}
$\begin{array}{r}\text { Frequency } \\
\text { of CS use }\end{array}$ \\
\end{tabular}} \\
\hline & 7 & 8 & 9 & 10 & 11 & 18 & 19 & 20 & 21 & 30 & \\
\hline Error repair & 4 & 6 & 7 & 3 & 1 & 3 & 4 & & 8 & 2 & 38 \\
\hline Appropriacy repair & 1 & 3 & & 2 & 2 & 1 & 5 & 2 & 3 & 2 & 21 \\
\hline Different repair & 2 & 3 & & 1 & 2 & 2 & & & & 2 & 12 \\
\hline Rephrasing repair & & & 1 & 2 & 1 & & 1 & 1 & 1 & & 7 \\
\hline Own-accuracy checks & 1 & & & & & & & & & & 1 \\
\hline $\begin{array}{l}\text { Total number of CS } \\
\text { per participant }\end{array}$ & 138 & 111 & 75 & 98 & 138 & 116 & 170 & 123 & 66 & 141 & \\
\hline $\begin{array}{l}\text { Total number of } \\
\text { different types of CS } \\
\text { per participant }\end{array}$ & 18 & 16 & 8 & 16 & 18 & 15 & 17 & 14 & 14 & 14 & \\
\hline
\end{tabular}

As can be observed in Table 7, the number of communication strategies used by advanced learners in session 1 ranged from 66 to 170 . In total, 30 different types of strategies were used by the advanced group. Four CSs were used by all pre-intermediate participants: grammatical reduction, unfilled pauses, lengthening a sound and self-repetitions. It is also noteworthy that five types of strategies were used, each, only once, by a different participant: foreignizing by participant 19; grammatical word coinage by participant 30; direct appeal by participant 7 ; phonological substitution by participant 19 , and self-accuracy check by participant 7 .

In this session, as has already been said, a great amount of grammatical reduction, unfilled pauses, umming and erring, lengthening and self-repetitions was also frequently applied by advanced learners, following the pattern of preintermediate and intermediate learners. This result is, at least, puzzling, since more proficient learners were expected to use fewer grammatical reduction strategies and unfilled pauses than the less proficient ones.

The use of umming and erring, lengthening and self-repetitions also showed a high frequency use in session $1-156,220$ and 180 instances, respectively. In spite of not being used by all participants, transfer, phonological retrieval and the different types of self-corrections (error repair, appropriacy repair, different repair and rephrasing repair) were frequently employed by advanced learners as well, with 37,23 , and 78 instances, respectively. 
As advanced learners are considered to be more experienced language users with a greater ability to reflect upon the language system, it was expected that they would apply more self-repairs than less proficient learners. However, results show that, in session 1, advanced L2 speakers surpassed only preintermediate learners ( 78 versus 25 corrections), keeping almost the same score of the intermediate group (78 versus 69 repairs).

In addition, it is interesting to observe that the frequency of code-switching strategies was not very high - only 9 instances, which were applied by only 3 participants in session 1. According to Faerch and Kasper (1983), code-switching is a CS which is not considered to lead to IL development, since it is usually based on the L1 linguistic system, thus, presenting less potential learning effect (FAERCH and KASPER, 1983). Legenhausen (1991) claims that not all kinds of code switching are related to lack of a lexical item or semantic appropriateness, and that they may serve as discourse strategies applied to achieve specific communicative goals. According to the author, code-switchings can also be viewed as a speech mode, used by learners to emphasize their cultural identity. However, in the present study, code-switching seems to have been applied to replace an L2 lexical item which was not available at the moment.

Another surprising result is the use of message abandonment strategies. Although the frequency use of this CS by advanced learners did not surpass intermediate learners in the same session (7 versus 10 instances, respectively), more proficient learners were expected to cope with communicative difficulties in a more effective manner and to be able to communicate by using their available IL resources, without abandoning the intended goal.

TABLE 8

Types and frequency of use of CSs in the Advanced group - session 2

\begin{tabular}{|c|c|c|c|c|c|c|c|c|c|c|c|}
\hline \multirow[b]{2}{*}{ Types of CS } & \multicolumn{10}{|c|}{ Participants } & \multirow{2}{*}{\begin{tabular}{|r}
$\begin{array}{r}\text { Frequency } \\
\text { of CS use }\end{array}$ \\
\end{tabular}} \\
\hline & 7 & 8 & 9 & 10 & 11 & 18 & 19 & 20 & 21 & 30 & \\
\hline Message abandonment & 1 & & & 1 & 2 & & & 1 & 1 & & 6 \\
\hline $\begin{array}{l}\text { Message reduction } \\
\text { Message replacement }\end{array}$ & & 1 & 1 & 1 & 1 & & 2 & & & & 6 \\
\hline Code-switching & 1 & & & 1 & 2 & 1 & & 2 & & & 7 \\
\hline Approximation & & & 2 & 1 & 1 & 1 & 2 & & & 1 & 8 \\
\hline All-purpose-words & 1 & & & 1 & & & & & & & 2 \\
\hline
\end{tabular}


(continuação)

\begin{tabular}{|c|c|c|c|c|c|c|c|c|c|c|c|}
\hline \multirow[b]{2}{*}{ Types of CS } & \multicolumn{10}{|c|}{ Participants } & \multirow{2}{*}{$\begin{array}{r}\text { Frequency } \\
\text { of CS use }\end{array}$} \\
\hline & 7 & 8 & 9 & 10 & 11 & 18 & 19 & 20 & 21 & 30 & \\
\hline Complete omission & 1 & 3 & 1 & & 1 & 1 & 3 & & & & 10 \\
\hline Foreignizing & & & & 1 & 1 & & 1 & 1 & & 1 & 5 \\
\hline $\begin{array}{l}\text { Grammatical word } \\
\text { coinage }\end{array}$ & & & & 1 & & & & & & & 1 \\
\hline Literal translation & & & & 1 & & & & & & & 1 \\
\hline Circumlocution & & & & & & & & & & & \\
\hline Semantic word coinage & & & & & & & & & & & \\
\hline Restructuring & 1 & 2 & 2 & 1 & 2 & & 1 & & & 1 & 10 \\
\hline Direct appeal & & & & & & & & & & & \\
\hline Indirect Appeal & 1 & & & & & & & & & & 1 \\
\hline Overgeneralization & 4 & & & 1 & 2 & & 4 & & 2 & & 13 \\
\hline Transfer & 1 & 11 & 2 & 4 & 2 & 2 & 3 & 4 & 1 & 1 & 31 \\
\hline Grammatical Reduction & 4 & 23 & 2 & 17 & 25 & 11 & 26 & 15 & 5 & 16 & 144 \\
\hline Phonological Retrieval & 3 & 1 & & 1 & 6 & 1 & 3 & & & 1 & 16 \\
\hline Phonological Substitution & & & & & & & 1 & & & & 1 \\
\hline $\begin{array}{l}\text { Phonological Reduction } \\
\text { (mumbling) }\end{array}$ & & 1 & & & & & & 1 & 2 & 1 & 5 \\
\hline Filled pauses (fillers) & & 1 & & 1 & & 2 & & & 1 & & 5 \\
\hline Unfilled pauses & 28 & 7 & 9 & 19 & 26 & 9 & 23 & 43 & 33 & 16 & 213 \\
\hline Umming and erring & 23 & 25 & 3 & 10 & 27 & 10 & 35 & 10 & 3 & 21 & 167 \\
\hline Lengthening a sound & 9 & 3 & 18 & 20 & 40 & 3 & 37 & 5 & 2 & 51 & 188 \\
\hline Self-repetitions & 18 & 43 & 20 & 36 & 35 & 25 & 23 & 11 & 8 & 24 & 243 \\
\hline Error repair & 1 & 1 & 3 & 2 & 5 & 2 & 6 & 2 & & 3 & 25 \\
\hline Appropriacy repair & & 6 & 4 & 3 & 1 & 2 & 3 & 1 & 2 & 2 & 24 \\
\hline Different repair & & 2 & 1 & 1 & 2 & & 3 & 2 & & 5 & 16 \\
\hline $\begin{array}{l}\text { Rephrasing repair } \\
\text { Own-accuracy checks }\end{array}$ & 2 & 4 & 2 & 1 & 1 & 1 & 1 & & & 2 & 14 \\
\hline $\begin{array}{l}\text { Total number of CS } \\
\text { per participant }\end{array}$ & 99 & 134 & 71 & 125 & 182 & 71 & 176 & 98 & 60 & 146 & \\
\hline $\begin{array}{l}\text { Total number of } \\
\text { different types of CS } \\
\text { per participant }\end{array}$ & 16 & 16 & 15 & 22 & 19 & 14 & 17 & 13 & 11 & 15 & \\
\hline
\end{tabular}


The number of CSs used by advanced learners in session 2, as can be observed in Table 8, ranged from 60 to 176. The strategies most applied in this session were: grammatical reduction - 144 instances; unfilled pauses - 213 examples; umming and erring - 167 uses; lengthening - 188 instances, selfrepetitions -243 examples. These strategies were also applied by all participants, including transfer. The CSs of grammatical word coinage, literal translation, indirect appeal, and phonological substitution were used, each, only once by participants 10,7 and 9, respectively. Additionally, the category of self-repairs presents a relatively high frequency among advanced learners. The second session surpassed sessions 1 and 3 in the total number of self-corrections, including error, appropriacy, different and rephrasing repairs - 79 instances in session 2; 78 uses in session 1 , and 51 in session 3. Two categories of CSs showed a decrease in frequency from session 1 to session 2 in the advanced group: phonological retrieval and message abandonment. The former was employed 23 times in session 1 and 16 in session 2, which might indicate some improvement in learners' speech production processing, more particularly in the phonological encoding phase. The latter, message abandonment, decreased from 7 in session 1 to 6 in session 2. Although a slight decrease, this may suggest that as learners keep acquiring and practicing the L2, they are likely to improve their ability to manage their communicative problems through achievement strategies, as termed by Faerch and Kasper (1983). In other words, they avoid reducing the communicative intention and try alternative ways of encoding the message.

TABLE 9

Types and frequency of use of CSs in the Advanced group - session 3

\begin{tabular}{|c|c|c|c|c|c|c|c|c|c|c|c|}
\hline \multirow[b]{2}{*}{ Types of CS } & \multicolumn{10}{|c|}{ Participants } & \multirow{2}{*}{$\begin{array}{r}\text { Frequency } \\
\text { of CS use }\end{array}$} \\
\hline & 7 & 8 & 9 & 10 & 11 & 18 & 19 & 20 & 21 & 30 & \\
\hline Message abandonment & & & & & & & 1 & & 1 & & 2 \\
\hline Message reduction & & 1 & & & & & & & & & 1 \\
\hline Message replacement & & & & & & & & & & & \\
\hline Code-switching & & 3 & & 2 & & 1 & 4 & 1 & 1 & & 12 \\
\hline Approximation & 4 & & 1 & 1 & 5 & 1 & 4 & 1 & 1 & 2 & 20 \\
\hline All-purpose-words & & & & & & & 1 & & 1 & & 2 \\
\hline Complete omission & & 2 & & & & 1 & & & 1 & & 4 \\
\hline
\end{tabular}

(continua) 
(continuação)

\begin{tabular}{|c|c|c|c|c|c|c|c|c|c|c|c|}
\hline \multirow[b]{2}{*}{ Types of CS } & \multicolumn{10}{|c|}{ Participants } & \multirow{2}{*}{$\mid \begin{array}{r}\text { Frequency } \\
\text { of CS use }\end{array}$} \\
\hline & 7 & 8 & 9 & 10 & 11 & 18 & 19 & 20 & 21 & 30 & \\
\hline Foreignizing & & & & 1 & & & & 1 & & & 2 \\
\hline $\begin{array}{l}\text { Grammatical word } \\
\text { coinage }\end{array}$ & & & & 1 & & & & & & & 1 \\
\hline Literal translation & 1 & 1 & & 1 & & & 1 & 2 & & & 6 \\
\hline Circumlocution & & & & 2 & & 1 & & & & & 3 \\
\hline Semantic word coinage & & & & & & & & & & & \\
\hline Restructuring & 1 & 1 & & & & & & & & 2 & 4 \\
\hline Direct appeal & & & 1 & & & & & & 1 & & 2 \\
\hline Indirect Appeal & 1 & 1 & 1 & & 2 & 1 & & & & & 6 \\
\hline Overgeneralization & 1 & 2 & & & & & 3 & & & 2 & 8 \\
\hline Transfer & & 1 & 1 & 3 & & 1 & 2 & 5 & & 1 & 14 \\
\hline Grammatical Reduction & 16 & 15 & 7 & 18 & 12 & 11 & 19 & 13 & 6 & 13 & 130 \\
\hline Phonological Retrieval & & 4 & 2 & & 2 & & 1 & 1 & 1 & 1 & 12 \\
\hline Phonological Substitution & 1 & & & & & & & & & 1 & 2 \\
\hline $\begin{array}{l}\text { Phonological Reduction } \\
\text { (mumbling) }\end{array}$ & 2 & 2 & & 2 & & & & & & & 6 \\
\hline Filled pauses (fillers) & & 1 & & 2 & 1 & & & 1 & & & 5 \\
\hline Unfilled pauses & 16 & 12 & 17 & 13 & 26 & 14 & 23 & 26 & 15 & 13 & 175 \\
\hline Umming and erring & 14 & 10 & 1 & & 10 & 6 & 4 & 2 & & 3 & 50 \\
\hline Lengthening a sound & 29 & 19 & 21 & 27 & 23 & 13 & 12 & & 11 & 33 & 188 \\
\hline Self-repetitions & 14 & 19 & 16 & 10 & 13 & 14 & 31 & 5 & 2 & 6 & 130 \\
\hline Error repair & 1 & 3 & & 3 & 2 & 2 & 3 & 3 & 3 & 1 & 21 \\
\hline Appropriacy repair & 3 & 2 & 2 & 3 & 3 & 2 & & 1 & 1 & 4 & 21 \\
\hline Different repair & & & & & & & 2 & & & 1 & 3 \\
\hline Rephrasing repair & 1 & 1 & 1 & & & 1 & 2 & & & & 6 \\
\hline Own-accuracy checks & & & & & 2 & & & & & & 2 \\
\hline $\begin{array}{l}\text { Total number of CS } \\
\text { per participant }\end{array}$ & 105 & 100 & 71 & 88 & 101 & 69 & 113 & 62 & 46 & 83 & \\
\hline $\begin{array}{l}\text { Total number of } \\
\text { different types of CS } \\
\text { per participant }\end{array}$ & 15 & 19 & 12 & 14 & 12 & 14 & 16 & 13 & 14 & 14 & \\
\hline
\end{tabular}


Table 9 displays the types and frequency of use of CSs found in the speech of Advanced learners in session 3. In this session, the number of CSs applied by participants ranged from 46 to 113 . Following the same pattern of the previous sessions (1 and 2), advanced learners employed a high number of grammatical reductions - 130 uses; unfilled pauses - 175 uses; umming and errings - 50 uses; lengthening sounds -188 uses, and self-repetitions -130 uses. The use of these CSs may indicate a common set of strategies applied across proficiency levels, since all groups, despite some differences in the frequency of use, applied grammatical reductions, unfilled pauses, lengthening a sound, umming and urring and self-repetitions.

In total, 29 different types of strategies were used by the advanced group in session 3. Three CSs were used by all advanced participants: grammatical reduction, unfilled pauses, and self-repetitions. It is also interesting to note that three types of strategies were used, each, by a different participant: message reduction, used only once by participant 8 , grammatical word coinage, used once by participant 21 , and own-accuracy checks, used twice by participant 11 . Selfrepairs were also often applied in session 3, thus, suggesting that advanced learners were very concerned with the quality of their language output. Error repair and appropriacy repair were the most used strategies -21 instances each.

A noteworthy result is the increased use of approximation strategies from session 1 (5 instances) to session 2 ( 8 instances) and from session 2 to session 3 (20 instances). Such an increase might indicate that as learners keep on acquiring more knowledge about the language, they become able to handle the linguistic resources they possess in order to communicate items they do not know or that are still inaccessible. The ability to use their linguistic knowledge to approximate concepts may help learners to foster the automatization of some aspects of their IL system - an essential step in the learning process (FAERCH and KASPER, 1983). It was also noted the use of 2 self-accuracy checks made by participant 11 in session 3, thus indicating he was uncertain about a specific item in his speech.

In the advanced group, in turn, it was noticed that participants who employed more CSs in general, varied the number of different types of strategies. In session 1 , for instance, participant 7 used a total of 138 CS of 18 different types; participant 11 used 139 CSs also spread over 18 categories of strategies, and participant 19 used $170 \mathrm{CSs}$ of 17 different types. However, there are also participants who used many CSs, but of fewer different types. For example, participant 20 used, 
in total, $123 \mathrm{CSs}$ and participant 30 used $138 \mathrm{CSs}$, both of 14 different categories. Another group concerns the participants who used fewer CSs than the mean of the session (117.5 CSs per participant), but presented a relatively larger repertoire if compared to the mean -15 different types per participant. They are: participant 8 , who used 111 CSs, and participant 10 , who applied $98 \mathrm{CSs}$, both of 16 different types of strategies.

Session 2 follows a similar pattern. Three cases were identified - (i) participants who used more CS of a greater number of different types; (ii) participants who applied more CS within fewer different types and (iii) participants who used fewer CS of a great number of different types. In the first pattern are: participant 10 who used, a total of 125 CS of 22 different types; participant 11 who applied 182 CS of 19 different types; participant 19 who used 176 CS spread over 17 different kinds, and participant 8 who used, a total of $134 \mathrm{CS}$ of 16 different types. In the second pattern there is only participant 30 who used 146 CS of 15 different types. Finally, in the third pattern, there is participant 7 with 99 CS of 16 different types.

Considering that the mean of CSs use in session 3 is 83,5 strategies per participant, it is possible to state that this session shows the same pattern found in the first 2 sessions, except for the fact that the third pattern (fewer CSs of more different types) cannot be applied here. In the first pattern (more CSs and a larger number of different types of strategies) there are 3 learners: participant 8 who applied, in total, $100 \mathrm{CSs}$ of 19 different types; participant 7 who used $105 \mathrm{CSs}$ of 15 different types and participant 19 who used 110 CSs of 16 different categories. In the second pattern (more CSs applied and fewer different types of strategies) are included participant 10 who used 88 CSs of 14 different types and participant 11 who applied 101 CSs of 12 different kinds.

\subsection{Overall Discussion: Communication Strategies and the relationship among L2 proficiency, frequency of occurrence and types of CSs}

A quantitative and a qualitative difference were expected to occur in the use of CSs between pre-intermediate, intermediate and advanced learners. That is, the total number of CSs used by L2 learners was expected to decrease across proficiency levels, whereas the types of strategies would go from less sophisticated ones, such as message abandonment, message reduction, message replacement, 
code-switching, complete omission, appeals for help and pauses, to more elaborate strategies such as restructuring, self-corrections, word coinage, overgeneralization, approximation, and circumlocution. However, this prediction was not totally supported by the results. Concerning the total number of CSs used, it was found that the intermediate group surpassed both - pre-intermediate and advanced groups. This finding may be accounted for by the following factors.

First, more proficient learners have a greater amount of L2 knowledge at their disposal, thus being able to handle the communicative breakdowns that might occur during communication in a more effective fashion and thereby resorting less frequently to CSs. Therefore, it could be that, in the present study, the advanced group used fewer strategies than the intermediate group because of their greater knowledge of the language. This finding is in line with Chen (1990) and Paribahkt (1985), who concluded that better learners applied fewer CSs due to their increased command of the L2.

Second, in the case of pre-intermediate learners, it might be possible that their low-proficiency level was too low to foster a more consistent use of CSs. Such a finding is corroborated by Poulisse and Schils (1989) who suggest that, in order for differences among proficient levels to be considered significant, it seems to be necessary that learners reach a minimal proficient level required for strategic language use. Hence, learners from a too low-proficiency level would not possess the minimal L2 knowledge to deal with the several communicative flaws they may encounter in the course of communication.

Intermediate learners also presented a larger repertoire of CSs if compared to pre-intermediate and advanced learners. By analyzing intermediate learners' characteristics and their behavior in class (two classes from each group were observed prior to data collection), it seems plausible to infer that the great number of different types of CSs used is related to the learning profile of the group. First, this group of learners was highly motivated to learn and most of them enjoyed participating in classroom activities. Second, when they were encouraged to talk, they seemed more concerned about communicating, therefore paying less attention to speaking "correctly" (accurately). This probably made them resort to all possible CSs at their disposal in order to accomplish their communicative goals.

Similarly, regarding the types of CSs used, it was expected that advanced learners would apply more sophisticated or elaborate strategies than lowerproficiency learners, due to their wider amount of L2 knowledge. Instead, results 
indicate a group of CSs used across the three proficiency levels, with a high frequency of occurrence. The CSs mostly applied across the three groups of learners in the present study were: transfer, grammatical reduction, unfilled pauses, umming and erring, sound-lengthening and self-repetition. In the case of transfer and grammatical reduction strategies, it is important to have in mind that bilingual speech production has some specific characteristics. For well accepted reasons, L2 speakers' knowledge does not attaim the same status of as their L1 knowledge - they usually show a smaller number of lexical items available; their grammatical, semantic and morphological knowledge is underdeveloped and problems with phonological encoding are commonplace (POULISSE, 1997), which may lead L2 learners to experience difficulties in formulating oral messages, therefore producing speech somewhat ungrammatical, full of pauses, hesitations, phonologically problematic, and slow. Probably, due to these processing constraints and having an entire L1 language system at their disposal, learners decided to transfer $\mathrm{L} 1$ features and/or make use of grammatical reduced forms so that they could communicate.

With regard to time-pressure related CSs - unfilled pauses, umming and erring, sound-lengthening and self-repetition, Dörnyei and Kormos (1998) argue that these strategies serve as tools for learners to gain time during speech processing. According to the authors, L2 speech production requires more attentional resources than speech processing in L1, since procedures are less automatized. Automatic processes are considered to be responsible for skilled performance of cognitive tasks (SCHMIDT, 1992). According to Levelt (1989), in order to produce fast and continuous speech, processing components should be highly automatized and work in parallel. When L2 speakers note they are having problems in communicating due to some processing constraint, they usually resort to CSs that help them to provide more time to process speech and maintain an air of fluency, by holding the floor and carrying on communication (DÖRNYEI and KORMOS, 1998; EJZENBERG, 2000)

The lack of substantial type-related differences among the three proficiency groups in the present study may also be accounted for by the nature of the elicitation tasks. Because learners were performing monologic tasks, they might have felt that there was no need to exchange information since there was no interlocutor to interact with them. This might have led them to resort to those CSs which were effortlessly and less cognitively demanding. According to Poulisse (1993), when L2 speakers are confronted with communicative problems, they 
seem to follow two general principles of communication: (1) the Least Effort Principle and (2) the Cooperative Principle. In the former, learners choose to resort to CSs which require less processing effort and, in the latter, they tend to use the CSs which are more comprehensible for their interlocutors. In the present study, L2 learners might have been more prone to following the Least Effort Principle, due to the nature of the tasks they performed: monologic tasks.

Another possible reason that may have contributed to the use of a common set of CSs by the three proficiency groups across sessions can be accounted, on the one hand, by task-repetition effects on performance. Learners' previous experiences with the narrative task in the first session might have helped them in the following sessions, since they might have kept track of how they solved a particular communicative problem and decided just to apply the same procedures when a new problem arose. As explained by Bygate (2001, p.29), "this proposition assumes that part of the work of conceptualization, formulation and articulation carried out on the first occasion is kept in the learners' memory store and can be reused on the second occasion....'. Even if one argues that these task-repetition effects suggested by Bygate only apply for situations in each the very same task is repeated over time, it is plausible to suggest that, although the tasks of the present study had different topics, they were all narratives (retellings of past events) and were supposed to have the same intrinsic characteristics. This claim was corroborated in a very recent study by Prebianca and Silveira (2007) who investigated the validity of the three oral tasks performed by the participants of the present study. Results showed that the frequency of occurrence of CSs in the picture-based narrative was smaller than in the two topic-based narratives. However, more important, is the fact that, although both topic-based narratives had different topics, this seem not to have led participants to apply a greater number of different types of CSs, showing that they consistently used the same pool of strategies over tasks.

\section{Final remarks}

As previously stated, the present study was carried out in order to investigate which types of communication strategies are applied by learners with different proficiency levels and their respective frequency of occurrence. The use of strategies in communication was assessed by analyzing the oral samples 
of $30 \mathrm{~L} 2$ learners, and identifying and classifying them according to a framework proposed by Dörnyei and Kormos (1998).

Results demonstrated that, although the intermediate group made use of a larger repertoire of strategies, there was no great difference concerning the types of CSs used by learners within different phases of the learning process. It was clearly notable that there was a common group of CSs being used across proficiency levels. The CSs more frequently employed by all L2 learners were: transfer, grammatical reduction, unfilled pauses, umming and erring, soundlengthening, and self-repetitions. The frequency distribution among these most used categories of CSs was also high at all levels. Concerning all instances of strategy use by all learners, the pre-intermediate learners applied a total of 790 CSs in session 1, 871 in session 2, and 874 in session 3, followed by advanced learners, who used 1175 strategies in the first session, 1144 in the second, and 835 in the third one. Intermediate learners employed considerably more CSs than the other participants from other proficiency levels: 1227, 1206, and 787 CSs in sessions 1,2 and 3 , respectively.

According to the above results, it seems clear that, on the one hand, the present study did not succeed in gathering evidence in favor of a quantitative and a qualitative difference in the use of CSs between pre-intermediate, intermediate, and advanced L2 learners. On the other hand, the insights regarding the development of L2 strategic competence by less proficient learners might be a fruitful terrain to be explored, particularly for pedagogical reasons. In other words, the fact that the intermediate learners surpassed the pre-intermediate ones in the amount of CSs applied may be the most interesting result of the present study. This finding seems to suggest that less proficient learners may not be fully prepared to develop the use of CSs, since they are still in the beginning of the learning process and seem not to have enough L2 knowledge to take advantage from CSs use. As learners increase their knowledge of the L2, they may eventually learn how to use language more strategically so as to overcome their communicative difficulties. This assumption is corroborated by several studies in the area which showed that more proficient learners were able to use CSs more frequently and effectively than less proficient ones (BIALYSTOK, 1983; PARIBAHKT, 1985; PALMBERG, 1984; KUMARAVADIVELU, 1988; POULISSE and SCHILS, 1989).

From a pedagogical perspective, therefore, the teaching of CSs with the aim of helping learners to build their strategic competence in order to optimize communication has to be taken with caution. For less proficient learners, with less 
command of the L2, it might be more profitable to make them aware of the CSs they already know, giving them the opportunity to develop their metalinguistic awareness, by noticing the gaps in communication. However, for more proficient learners who have developed a greater amount of L2 knowledge, a different approach might be taken. That is, the common set of CSs that emerged from the present study might be useful for teachers in designing communicative tasks for the classroom which could help learners to: (i) engage in hypothesis-formation processes in order to test linguistic structures; (ii) automatize certain linguistic functions such as expressing uncertainty, paraphrasing, and using formulaic language; and (iii) expand their communicative resources, taking into account the less automatic nature of processing speech in L2 (FAERCH and KASPER, 1983; SKEHAN, 1996).

One of the major limitations of the present study was that learners' proficiency level was not assessed by any standardized proficiency test. The criterion used to select participants was to verify at which level they were enrolled in their English courses a week before data collection. This effect was clearer in the pre-intermediate group, which apparently had some learners who seemed to have the profile of beginners. For future research, standardized proficiency tests should be applied before data collection, in order to control the effects of language proficiency differences among participants.

\section{Notas}

${ }^{1}$ In the present paper, L2 will be used to refer both to second and foreign language. No distinction is made between these terms.

${ }^{2}$ The parser consists of a speech comprehension system, in charge of monitoring speech, both in terms of its morphological, phonological, semantic and syntactic representations (LEVELT, 1989, p. 13).

\section{References}

BIALYSTOK, E. Communication Strategies: a psychological analysis of secondlanguage use. Oxford: Basil Blackwell, 1990.

BIALYSTOK, E. Some factors in the selection and implementation of communication strategies. In: FAERCH, C.; KASPER, G. (Ed.). Strategies in interlanguage communication. London: Longman, 1983. p. 79-99. 
BONGAERTS, T.; POULISSE, N. Communication Strategies in L1 and L2: same or different? Applied Linguistics, 10 (3), p. 253-268, 1989.

BONGAERTS, T.; KELLERMANN, E.; BENTAGLE, A. Perspectives and proficiency in L2 referential communication. Studies in Second Language Acquisition, 9, p. 171-200, 1987.

BYGATE, M. Speaking. In: CARTER, R.; NUNAN, D. (Ed.). The Cambridge Guide to Teaching English to Speakers of Other Languages. Chapter 2. Cambridge: Cambridge University Press, 2001. p. 14-20.

CHEN, S. Q. A study of communication strategies in interlanguage production by Chinese EFL learners. Language Learning, 40, p. 155-187, 1990.

DÖRNYEI, Z.; KORMOS, J. Problem-Solving Mechanisms in L2 Communication: a psycholinguistic perspective. Studies in Second Language Acquisition, 20, p. 349-385, 1998.

EJZENBERG, R. The juggling act of oral fluency: a psycho-sociolinguistic metaphor. In: RIGGENBACH, H. (Ed.). Perspectives on fluency. Ann Arbor, MI: University of Michigan Press, 2000. p. 287-313.

FAERCH, C.; KASPER, G. Strategies in Interlanguage Communication. London: Longman, 1983.

FORTKAMP, M. B. M. Working Memory Capacity and Aspects of L2 Speech Production. Communication \& Cognition, 32, p. 259-296, 1999.

KASPER, G.; KELLERMAN, E. Communication Strategies: psycholinguistic and sociolinguistic perspectives. New York: Longman, 1997.

KELLERMAN, E. Compensatory Strategies in Second Language Research: a critique, a revision, and some (non-) implication for the classroom. In: PHILLIPSON, R.; KELLERMAN, E.; SELINKER, L.; SHARWOORD S.; SWAIN, M. (Ed.). Foreign/ second language pedagogy research: a commemorative volume for Claus Faerch. Clevedon, UK: Multilingual Matters, 1991.

KELLERMAN, E. ; BONGAERTS, T. ; POULISSE, N. Strategy and system in L2 referential communication. In: ELLIS, R. (Ed.). Second language acquisition in context. Englewood Cliffs, NJ: Prentice Hall, 1987.

KUMARAVADIVELU, B. Communication Strategies and Psychological Processes Underlying Lexical Simplification. IRAL, XXVI/4, p. 309-319, 1988.

LEGENHAUSEN, L. Code-switching in learners' discourse. IRAL, 29, p. 61-73, 1991.

LENON, P. Investigating Fluency in EFL: a qualitative approach. Language Learning, 40,3 , p. $387-417,1990$ 
LEVELT, W. J. M. Speaking: from intention to articulation. The Speaker as Information Processor. Cambridge, MA: MIT Press, 1989.

PALMBERG, R. Solving Communicative Problems in Interlanguage. Interlanguage Studies Bulletin, 8, n.2, p. 35-49, 1984

PARIBAKHT, T. Strategic competence and Language Proficiency. Applied Linguistics, 6, 2, p. 132-146, 1985.

POULISSE, N. Problems and solutions in the classification of compensatory strategies. Second Language Research, 3, p. 141-153, 1987.

POULISSE, N.; BONGAERTS, T.; KELLERMAN, E. The use of retrospective verbal reports in the analysis of compensatory strategies. In: FAERCH C.; KASPER, G. (Ed.). Introspection in second language research. Clevedon, UK: Multilingual Matters, 1987.

POULISSE, N.; SCHILS, E. The influence of task- and proficiency-related factors on the use of compensatory strategies: a quantitative analysis. Language Learning, 39 (1), p. 15-48, 1989.

POULISSE, N. Language Production in Bilinguals. In: DE GROOT, A. M. B.; KROLL, J. F. (Ed.). Tutorials in bilingualism: psycholinguistic perspectives. Mahwah, N. J.: LEA, 1997. p. 201-224.

POULISSE, N. A Theoretical Account of Lexical Communication Strategies. In: SCHEREUDER R.; WELTENS, B. (Ed.). The Bilingual lexicon. Amsterdam: John Benjamins, 1993.

PREBIANCA, G. V. V.; SILVEIRA, R. Tipos de tarefas e estratégias de comunicação: investigando a validade de narrativas baseadas em tópicos e em figuras. Revista de Estudos da Linguagem, 15, 1, p. 89-108, jan-jun, 2007.

SCHMIDT, R. Psychological mechanisms underlying second language fluency. Cambridge University Press, 1992. p. 357-385.

SELINKER, L. Interlanguage. IRAL, X/3, p. 209-231, 1972.

TARONE, E. Communication strategies, foreigner talk, and repair in interlanguage. Language Learning, 30, p. 417-431, 1980.

VARADI, T. Strategies of target language learner communication: message adjustment. In: FAERCH, C.; KASPER, G. (Ed.). Strategies in interlanguage communication. London: Longman, 1983. 


\section{Appendix I - Dörnyei and Kormos' (1998) taxonomy}

Types of CSs

A- Lexical

\begin{tabular}{ll}
\hline Message abandonment & Speakers leave the message unfinished due to language limitations \\
\hline Message reduction & $\begin{array}{l}\text { Speakers decide to avoid certain linguistic structures that are } \\
\text { problematic for them }\end{array}$ \\
\hline Message replacement & Speakers replace the original message by a new one \\
\hline Code-switching & Speakers insert L1 words in L2 speech \\
\hline Approximation & $\begin{array}{l}\text { The approximate use of a term, rather than the intended one. For } \\
\text { instance, rose for flower }\end{array}$ \\
\hline All-purpose-words & Speakers use broader terms such as thing, stuff, make, do \\
\hline Complete omission & Speaker leave the slot for the problematic item empty \\
\hline Foreignizing & Speakers use an L1 word to create a new L2 word \\
\hline Grammatical word coinage & $\begin{array}{l}\text { Speakers apply L2 rules to create a non-existing L2 word. For } \\
\text { instance, }- \text { ed for irregular verbs }\end{array}$ \\
\hline Literal translation & Speakers translate literally an item from L1 to L2 \\
\hline Circumlocution & $\begin{array}{l}\text { Speakers give examples, describe or illustrate the problematic } \\
\text { lexical item. }\end{array}$ \\
\hline Semantic word coinage & Speakers create a non existing L2 word, by using compound nouns \\
\hline Restructuring & Speaker give up the execution of the specific utterance \\
\hline Direct appeal & Explicit questions asking the interlocutor for help \\
\hline Indirect Appeal & $\begin{array}{l}\text { Implicitly way of expressing lack of knowledge or language } \\
\text { problems to the interlocutor }\end{array}$ \\
\hline
\end{tabular}

\section{B - Grammatical}

Overgeneralization

Transfer

Reduction

Description

Speakers leave the message unfinished due to language limitations problematic for them

Speakers replace the original message by a new one

The approximate use of a term, rather than the intended one. For instance, rose for flower Speakers use an L1 word to create a new L2 word instance, - ed for irregular verbs

Speakers translate literally an item from L1 to L2

Speakers give examples, describe or illustrate the problematic . al item.

Speaker give up the execution of the specific utterance

Implicitly way of expressing lack of knowledge or language

Speakers use L2 rules to construct a non existing L2 word

Speakers use L1 rules to create a non existing L2 lexical item

Speakers make use of simplified grammar hoping the interlocutor will be able to guess meaning from the context

\section{C- Phonological and Articulatory}

\begin{tabular}{ll}
\hline Retrieval & $\begin{array}{l}\text { Speakers keep saying incomplete or wrong forms until they reach } \\
\text { the best option. For example, tip of the tongue phenomenon./ }\end{array}$ \\
\hline Substitution & $\begin{array}{l}\text { Speakers use a word with similar sound to compensate for the } \\
\text { problematic item }\end{array}$ \\
\hline Reduction & $\begin{array}{l}\text { Speakers keep muttering a word they are not sure about the } \\
\text { pronunciation. }\end{array}$
\end{tabular}




\begin{tabular}{ll}
\hline Lexicalized (filled) pauses & Use of formulaic language. For example, well, you know, okay \\
\hline Unfilled pauses & Speakers remain silent for a period of time \\
\hline Umming and erring & Use of er, uh, uhm \\
\hline Lengthening a sound & $\begin{array}{l}\text { Speakers decide to length a string of sounds to gain time while } \\
\text { planning another utterance. For instance, I'mmm }\end{array}$ \\
\hline Self-repetitions & Speaker repeat the word or string of words they have just said \\
\hline Error repair & The correction of lapses in the speaker's output \\
\hline Appropriacy repair & Correction of inappropriate information \\
\hline Different repair & Change the speech plan and provide new information \\
\hline Rephrasing repair & $\begin{array}{l}\text { Speakers paraphrase a particular utterance because they are } \\
\text { uncertain about its correctness }\end{array}$ \\
\hline Rephrasing repair & $\begin{array}{l}\text { Speakers paraphrase a particular utterance because they are } \\
\text { uncertain about its correctness }\end{array}$ \\
\hline Comprehension checks & $\begin{array}{l}\text { Speakers ask question to ensure that the interlocutor has } \\
\text { understood the message }\end{array}$ \\
\hline Own-accuracy checks & $\begin{array}{l}\text { Repetition of words with question intonation in order to check if } \\
\text { what was said was correct }\end{array}$ \\
\hline
\end{tabular}

